\title{
A Flying Qualities Study of Longitudinal Long-Term Dynamics of Hypersonic Planes
}

Timothy H. Cox, G. Sachs, A. Knoll, and R. Stich

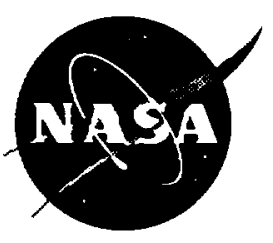

National Aeronautics and

Space Administration 


\section{A Flying Qualities Study of Longitudinal Long-Term Dynamics of Hypersonic Planes}

Timothy H. Cox

NASA Dryden Flight Research Center

Edwards, California

G. Sachs, A. Knoll and R. Stich Technical University of Munich Munich, Germany

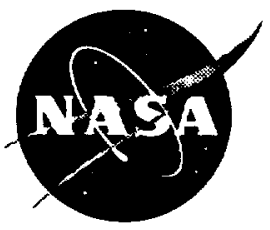

National Aeronautics and

Space Administration

Dryden Flight Research Center

Edwards, California 93523-0273 


\title{
A FLYING QUALITIES STUDY OF LONGITUDINAL LONG-TERM DYNAMICS OF HYPERSONIC PLANES
}

\author{
Timothy H. Cox* \\ NASA Dryden Flight Research Center \\ P.O. Box 273 \\ Edwards, California 93523-0273 \\ G. Sachs, ${ }^{* *}$ A. Knoll, ${ }^{\dagger}$ and R. Stich ${ }^{+\dagger}$ \\ Technische Universität München \\ Lehrstuhl f. Flugmechanik \\ Arcisstrasse 21 \\ 80290 München
}

\begin{abstract}
The NASA Dryden Flight Research Center and the Technical University of Munich are cooperating in a research program to assess the impact of unstable longterm dynamics on the flying qualities of planes in hypersonic flight. These flying qualities issues are being investigated with a dedicated flight simulator for hypersonic vehicles located at NASA Dryden. Several NASA research pilots have flown the simulator through welldefined steady-level turns with varying phugoid and height mode instabilities. The data collected include pilot ratings and comments, performance measurements, and pilot workload measurements. The results presented in this paper include design guidelines for height and phugoid mode instabilities, an evaluation of the tapping method used to measure pilot workload, a discussion of techniques developed by the pilots to control large instabilities, and a discussion of how flying qualities of unstable long-term dynamics influence control power design requirements.
\end{abstract}

\section{INTRODUCTION}

Much of the work in recent years focused on proposals and evaluations of hypersonic vehicle concepts. ${ }^{1}$ Many of these concepts required development of technology in fields such as structures and propulsion, and researchers have appropriately focused in these areas. However, deficiencies also exist in the flying qualities criteria for

\footnotetext{
*Aerospace Engineer.

**Director, Institute of Flight Mechanics and Flight Control. Associate Fellow AIAA.

+Research Assistant.

++ Research Assistant.

Copyright $(5) 1995$ by the American Institute of Aeronautics and Astronautics, Inc. No copyright is asserted in the United States under Tive 17 U.S. Code. The U.S. Government has a royalty-free license to exercise all rights under the copyright claimed herein for Governmental purposes. All other rights are reserved by the copyright owner.
}

hypersonic vehicles. One example where the criteria are deficient is in the impact of long-term dynamics on hypersonic flying qualities. ${ }^{2}$ The long-term dynamics consist of the phugoid and height modes of motion.

The current military standard ${ }^{3}$ does not adequately address the phugoid and height mode flying qualities requirements at hypersonic speeds. The phugoid flying qualities criteria are based on data from the subsonic regime. However, substantial differences exist between phugoid dynamics in subsonic and hypersonic flight. From the constant energy equation, a phugoid mode excited at high speeds produces greater altitude excursions for a given velocity excursion than a phugoid mode excited at low speeds. To make matters worse, tight control of altitude becomes more important in hypersonic flight than in subsonic flight because of engine performance sensitivity to dynamic pressure. Thus, the current criteria and data collected on the phugoid mode may not be applicable for the supersonic and hypersonic speed regimes.

The height mode is a mode of motion that becomes more significant in hypersonic (and supersonic) flight than in subsonic flight. The height mode, not addressed by the military standard, is typically a first-order response resulting from thrust variation with density gradient or speed. A more detailed description of the phugoid and height mode characteristics has previously been given. ${ }^{4}$

Berry addressed the issue of long-term dynamics ${ }^{5}$ by examining the impact of the propulsion system on the phugoid and height mode dynamics of a hypersonic lifting vehicle developed by Etkin. ${ }^{6}$ Berry discovered that airbreathing propulsion systems can produce flight regions of unstable height and phugoid modes. Berry thought that safe pilot control of these instabilities would have strong implications on redundancy management and backup systems required for the flight control system of hypersonic vehicles. The flying qualities impact of these unstable modes was, however, beyond the scope of his work. 
The need for this data led the NASA Dryden Flight Research Center and the Technical University of Munich into a cooperative research program to assess the flying qualities impact of unstable long-term dynamics on hypersonic planes. The primary objective of the research is to develop and validate flying qualities criteria for these dynamic characteristics of hypersonic vehicles. These issues are investigated with a dedicated flight simulator for hypersonic vehicles and an SR-71 aircraft located at NASA Dryden. Previous results from this cooperative research have been documented. ${ }^{7-10}$ The results presented in this paper are as follows:

- the design guidelines for height and phugoid mode instabilities

- the piloting techniques developed to control high degree of instabilities

- the evaluation of the tapping method used to measure pilot workload

- the influence of flying qualities of unstable longterm dynamics on control power design requirements

A

B

BTL basic tapping level

C output matrix

$C_{D_{v}} \quad$ change in the nondimensional drag coeffi-

$\mathrm{C}_{\mathrm{m}_{\mathrm{r}}}$

$\mathrm{C}_{\mathrm{m}_{e}}$

GHAME Generic Hypersonic Aerodynamic Model

$H \quad$ altitude, $\mathrm{ft}$

j

KEAS

$K_{\delta}$

LTL

$\mathbf{N}$

\section{NOMENCLATURE}

state matrix

control matrix cient with respect to speed changes Example

NASP

PML

$p$

$\mathrm{P}_{\mathrm{rms}}^{\prime}$

$P_{\text {rms }}$

$q$

$r$

rms

$\mathbf{s}$

$\mathbf{u}$

V

$\mathrm{X}$

$\mathbf{x}$

$\dot{x}$

y

$\alpha$

$\beta$

$\gamma$

$\Delta$

change in the nondimensional moment coefficient with respect to flightpath change

change in the nondimensional moment coefficient with respect to elevator change

a given run at each instability level

equivalent airspeed, knots

control system gain, $\mathrm{C}_{\mathrm{m}_{\mathrm{r}}} / \mathrm{C}_{\mathrm{m}_{\delta_{e}}}$

loaded tapping level

total number of runs flown at each instability
National Aerospace Plane

perceptual motor load

roll rate, $\mathrm{deg} / \mathrm{sec}$

Ims variation of the parameter altitude or $K E A S$ for a given run

rms variation of the parameter altitude or $K E A S$ across the total number of runs at a given instability

pitch rate, $\mathrm{deg} / \mathrm{sec}$

yaw rate, $\mathrm{deg} / \mathrm{sec}$

root mean square

Laplace operator

control input vector

true airspeed, $\mathrm{ft} / \mathrm{sec}$

element in matrix A modified for height mode variation

state vector

change of $x$ with respect to time

output vector

angle of attack, deg

sideslip angle, deg

flightpath angle, deg

change in a parameter

aileron position, rad

lateral stick deflection, in.

elevator position, rad

longitudinal stick deflection, in.

rudder position, rad

rudder pedal position, in.

throttle position, percent of full throw

dutch roll damping

pitch attitude, deg

bank angle, deg 


$$
\begin{array}{ll}
\psi & \text { heading angle, deg } \\
\omega_{d r} & \text { dutch roll frequency, rad/sec }
\end{array}
$$

\section{SIMULATOR DESCRIPTION}

The space shuttle and the National Aerospace Plane (NASP) programs ${ }^{11}$ successfully applied the fixed-base flight simulator used in this research in previous hypersonic flight research. For this study, the hypersonic vehicle aerodynamics and propulsion system were linearized models based on the Generic Hypersonic Aerodynamic Model Example (GHAME) at Mach 10 and an altitude of $110,000 \mathrm{ft}$. The GHAME model represents a generic, unclassified hypersonic vehicle incorporating six degrees of freedom; oblate earth equations of motion; and a turbojet, ramjet, and scramjet propulsion system combination. A simple, conventional control system (pitch rate feedback) designed for the linearized model provided Level 1 longitudinal short-term and lateral-directional flying qualities at the flight condition (fig. 1). ${ }^{3}$ The pilot-vehicle

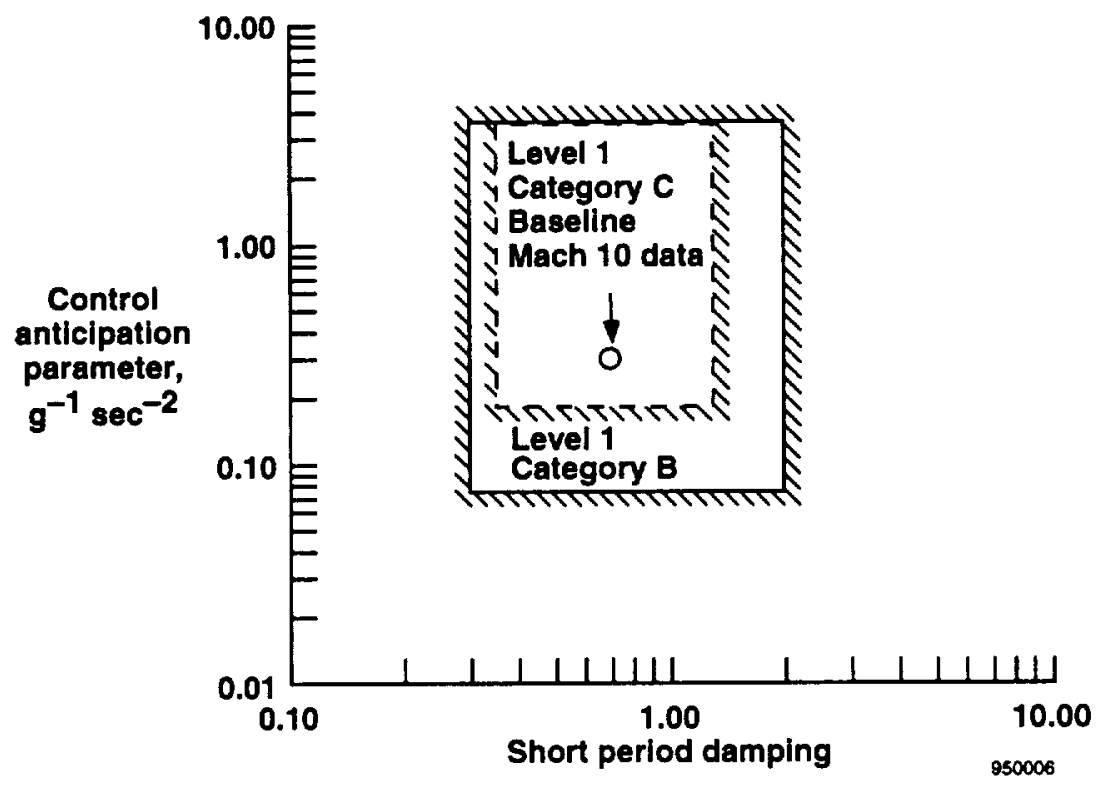

(a) Longitudinal short-period flying qualities design

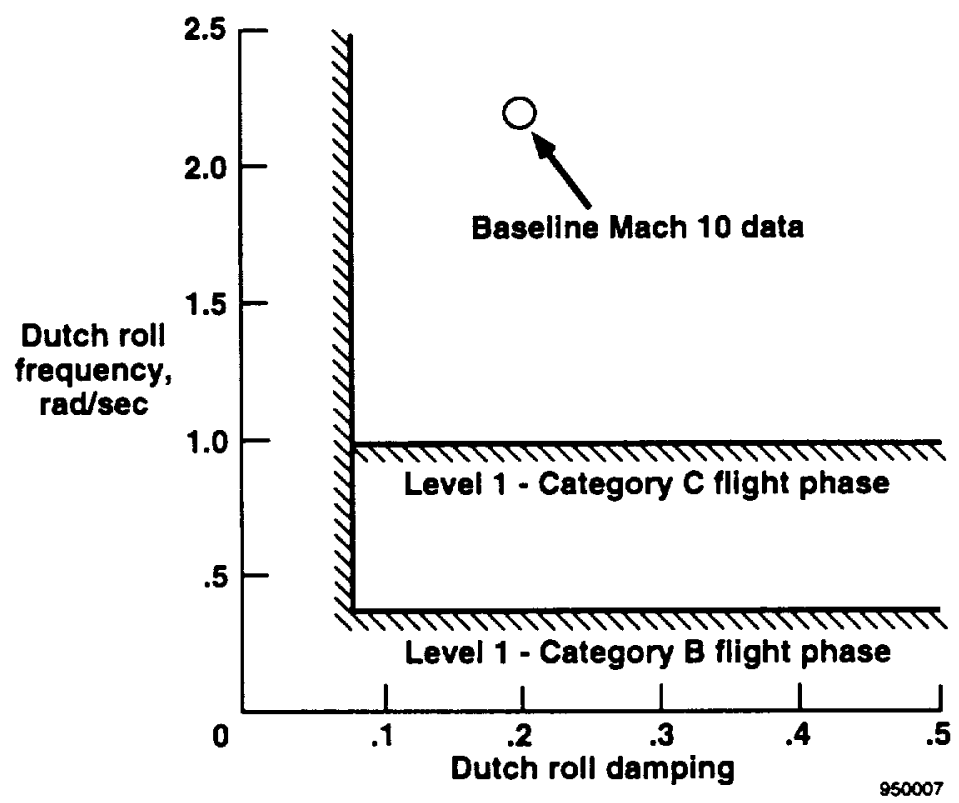

(b) Lateral-directional dutch roll flying qualities design.

Figure 1. Baseline Mach 10 flying qualities designs. 


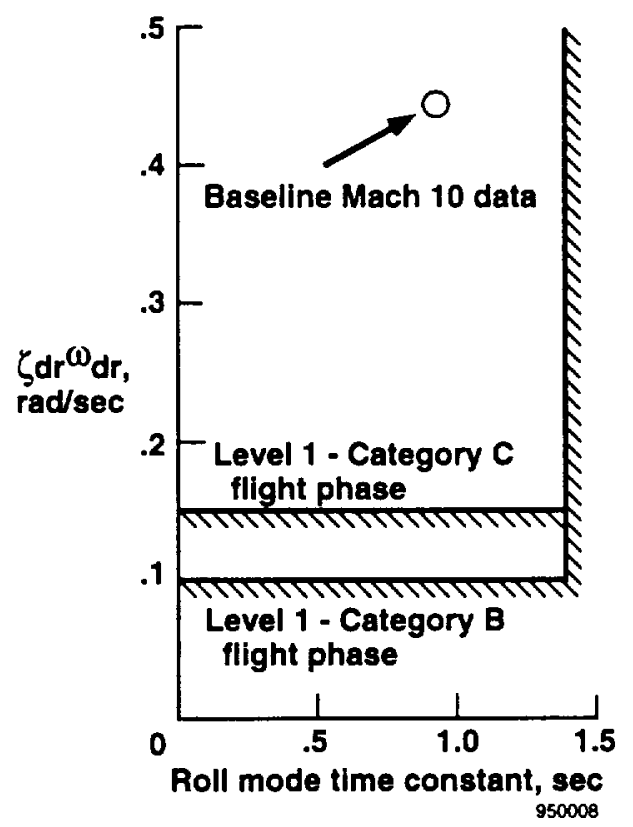

(c) Lateral-directional roll mode and dutch roll mode flying qualities design.

Figure 1. Concluded.

interface was a conventional center stick and rudder pedal. The appendix details the control system and linear equations of motion for the flight condition used in this study.

The cockpit instrumentation was based on a configuration used for the space shuttle. A central control panel and a simulated head-up display (fig. 2) provide the pilot with cues adequate to perform hypersonic maneuvering. Included in the head-up display were vertical and longitudinal accelerations, which proved useful for flightpath and speed control during space shuttle and NASP research. A fixed scale and arrow with rolling digits displayed vertical speed while a moving tape and arrow with rolling digits inside indicated altitude. A moving scale and fixed arrow displayed the heading with a resolution of $0.5^{\circ}$. Because of experience gained from initial simulator runs, it was decided to display an inertial vertical speed indicator in the form of a diamond on the pitch ladder.

\section{TEST PROCEDURE}

Pilots flew a well-defined steady-level turn to investigate the flying qualities implications and characteristics of various levels-of-height and phugoid instabilities. The definition of the maneuver was to perform a $30^{\circ}$ bank turn and capture a $12^{\circ}$ heading change. This maneuver had to be performed while immediately eliminating a vertical speed initial condition and maintaining constant airspeed and altitude.

Adequate performance was defined as capturing the final heading within $\pm 1^{\circ}$, maintaining speed within \pm 10 knots of the initial speed, and maintaining altitude within $\pm 600 \mathrm{ft}$ of the initial altitude.

Desired performance was defined as capturing the final heading within $\pm 0.5^{\circ}$, maintaining speed within \pm 5 knots of the initial speed, and maintaining altitude within \pm 300 $\mathrm{ft}$ of the initial altitude.

These performance criteria were chosen arbitrarily as reasonable but tight constraints and are shown in Table 1. The turning portion of the maneuver lasted approximately $2 \mathrm{~min}$ and termination of the maneuver occurred $1 \mathrm{~min}$ after capturing the final heading. Initial conditions were wings level at Mach 10 and an altitude of $110,000 \mathrm{ft}$. A vertical speed initial condition of $20 \mathrm{ft} / \mathrm{sec}$ was introduced to increase pilot workload.

Table 1. Adequate and desired performances.

\begin{tabular}{lcc}
\hline \hline \multicolumn{3}{c}{ Steady Level Turn } \\
\hline \multicolumn{1}{c}{ Controlled } & Adequate & Desired \\
parameters & performance & performance \\
Target heading & $\pm 1^{\circ}$ & $\pm 0.5^{\circ}$ \\
Target altitude & $\pm 600 \mathrm{ft}$ & $\pm 300 \mathrm{ft}$ \\
Trim speed $(K E A S)$ & $\pm 10 \mathrm{kn}$ & $\pm 5 \mathrm{kn}$ \\
\hline \hline
\end{tabular}

The pilots involved in the test program were experienced in high-speed flying. Their experience includes a wide spectrum of supersonic and hypersonic vehicles, including the SR-71, YF-12, and X-15. 


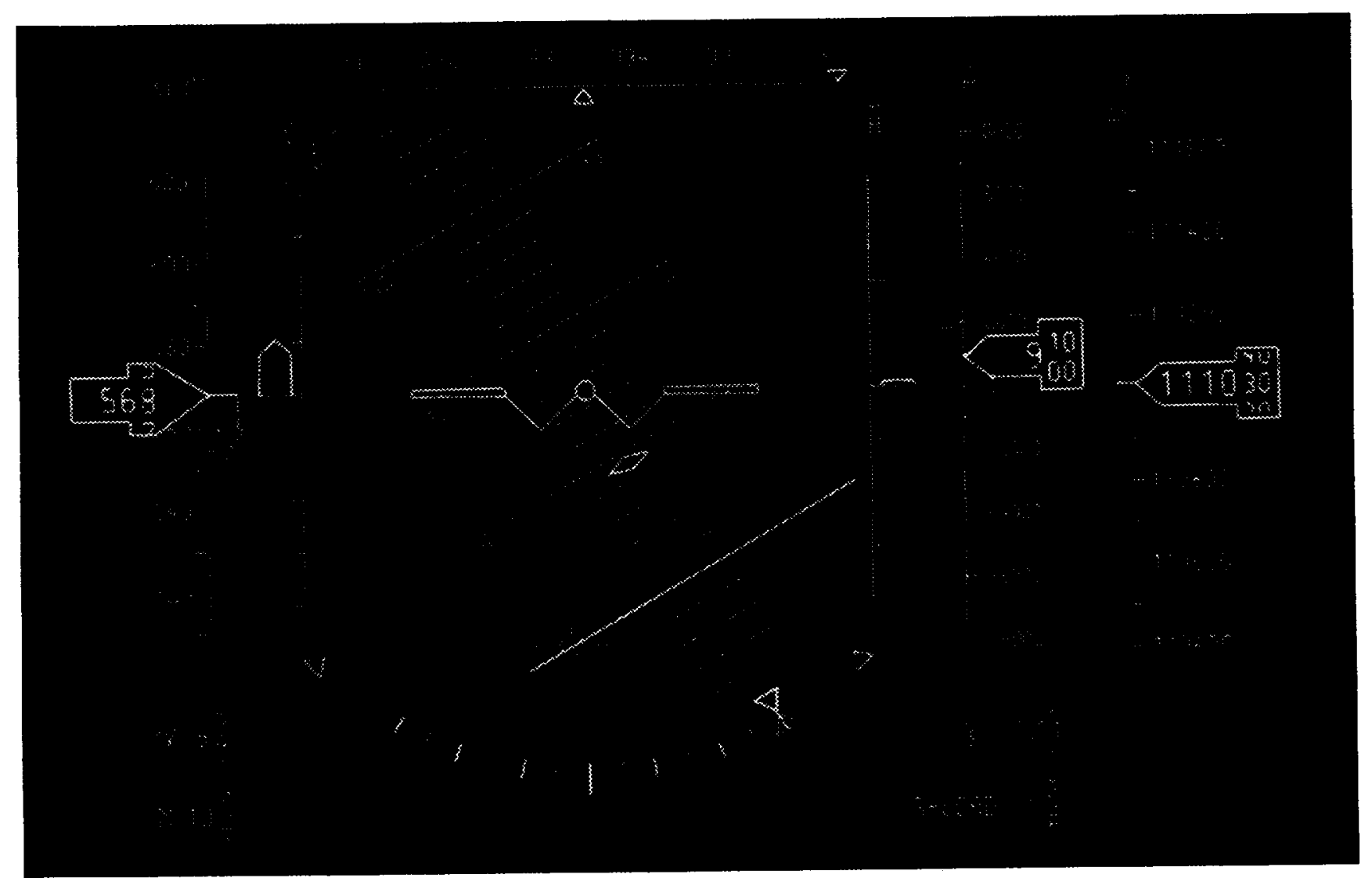

Figure 2. Simulated head-up display with modifications for hypersonic flight.

The pilots evaluated phugoid mode instabilities with time-to-double-amplitudes down to $1.7 \mathrm{sec}$ and height mode instabilities down to $3.5 \mathrm{sec}$, which were empirically determined limits of controllability for this study. Similar levels of instability were previously studied ${ }^{\text {t2 }}$ using a large supersonic transport model with an aperiodic phugoid time-to-double-amplitude of $4.6 \mathrm{sec}$ in the approach and landing condition. After each run, the pilot gave Cooper-Harper ratings ${ }^{13}$ (fig. 3), comments, and estimations of workload.

Figure 4 shows the workload scale developed for this study to provide insight on pilot workload independent of performance. For this workload scale, the pilot estimates the complexity of the side tasks possible while performing the maneuver. If the airplane is controllable, the pilot decides if simple side tasks (for example, radio communications) or complex side tasks (for example, flying in a complex air traffic control environment) are possible. After these distinctions, the pilot must estimate the level of compensation required to perform the maneuver, resulting in a rating from 1 to 13 .

A time history recorded from each test run provided information on pilot performance. Pilot performance was measured throughout the entire maneuver as the rootmean-square ( $\mathrm{rms})$ variation from the initial condition of the key parameters altitude and airspeed. Pilot performance was measured for only those test runs where the pilot maintained control. The following equation describes the summary of pilot performance for all the pilots at each instability: 


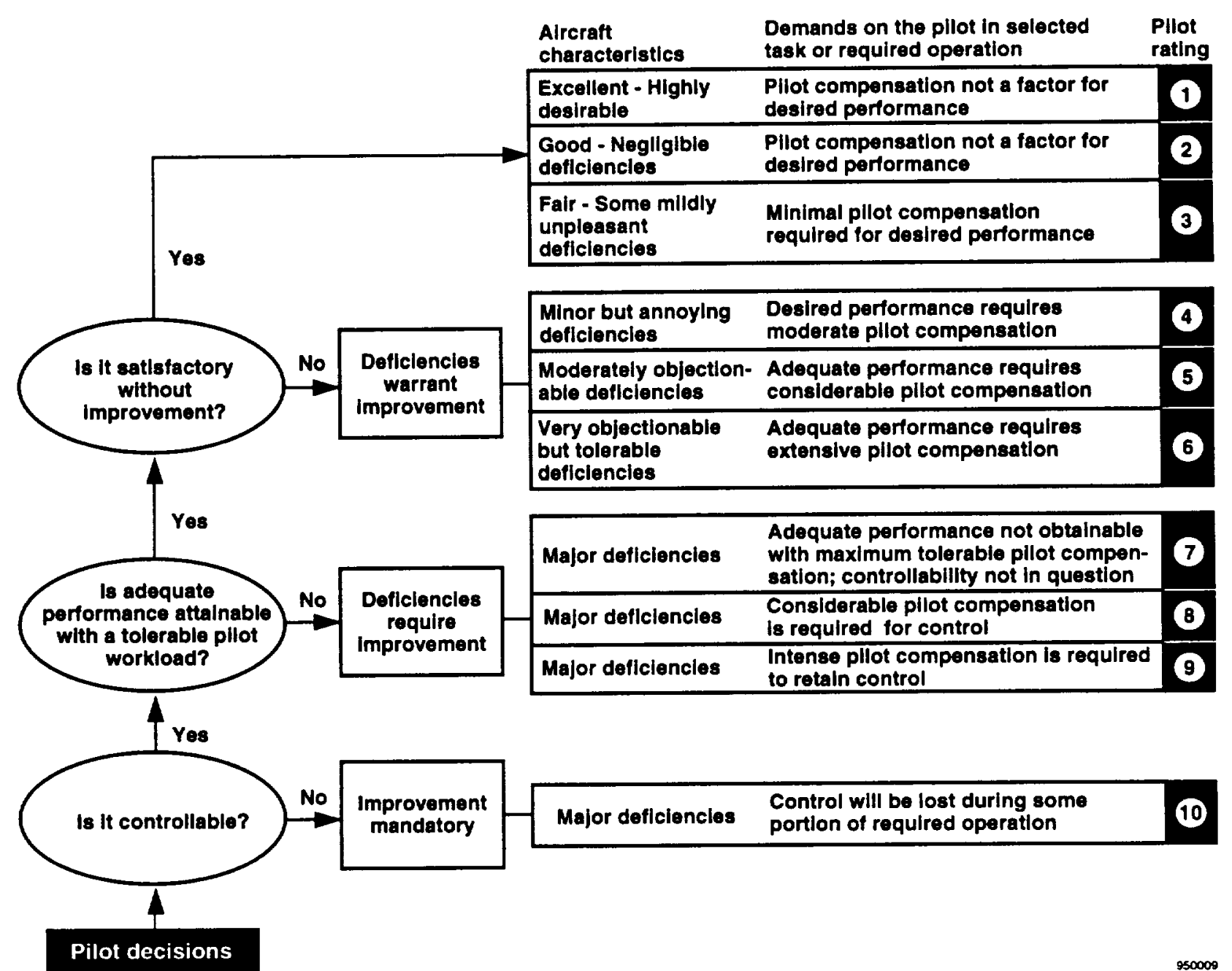

Pilot decisions

950009

Figure 3. Cooper-Harper rating scale. ${ }^{13}$ 


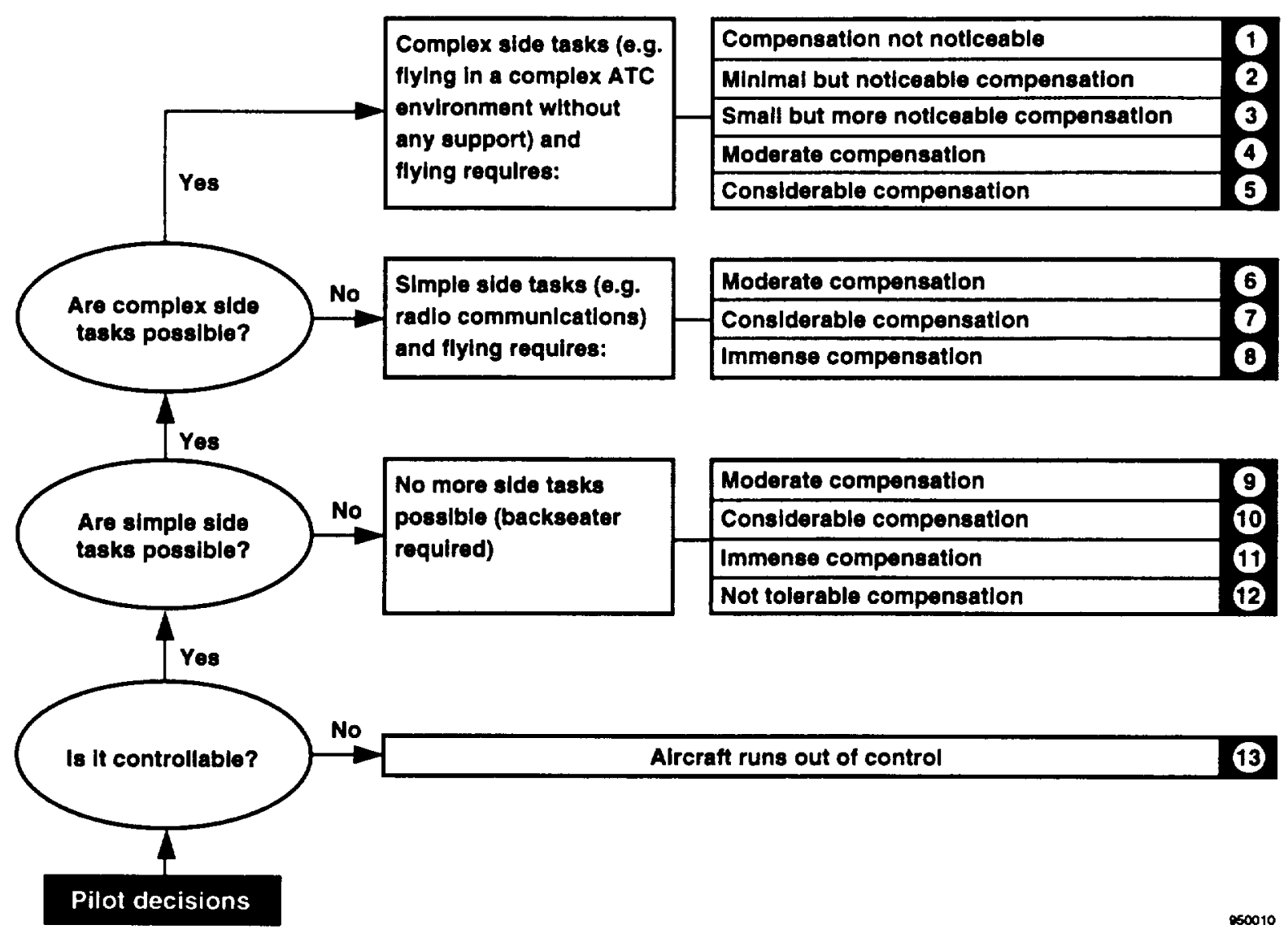

Figure 4. Workload rating scale.

$$
P_{r m s}=\sqrt{\frac{\sum_{i=1}^{N} P_{r m s}^{\prime 2}}{N}}
$$

where

$$
\begin{aligned}
& P=\text { altitude or airspeed } \\
& P_{r m s}^{\prime}=\text { the rms variation of the parameter about its } \\
& \text { initial condition for each run } \\
& \mathrm{N}=\text { the total number of runs flown at each } \\
& \text { instability level } \\
& P_{r m s}=\text { the rms variation about the initial condition } \\
& \text { across all runs at each instability }
\end{aligned}
$$

The $P_{\mathrm{rms}}$ parameter provides a summary of the performance achieved across all the runs at a given instability.
The phugoid and height mode instabilities were implemented through unstable feedback in the control system and modification of the aerodynamic models. Phugoid mode instabilities were implemented by positive feedback of flightpath angle (fig. 5). Height mode instabilities were implemented by modifying the drag coefficient due to speed, $C_{D_{y}}$ (fig. 6). This implementation allowed phugoid and height mode instabilities to be set independently from each other. The eigenvectors of the phugoid and height modes implemented with these methods were verified to have accurate characteristics. All phugoid instabilities evaluated were in the aperiodic region; however, the baseline phugoid case was periodic and neutrally stable. The baseline height mode case was stable with a time-to-half-amplitude of $77 \mathrm{sec}$. Tables 2 and 3 show the phugoid and height mode instabilities evaluated. 
Table 2. Phugoid mode instabilities evaluated.

\begin{tabular}{rcc}
\hline \hline$K_{\delta}$ & $\begin{array}{c}\text { Root location, } \\
\mathrm{rad} / \mathrm{sec}\end{array}$ & $\begin{array}{c}\text { Time to double } \\
\text { amplitude, sec }\end{array}$ \\
\hline 0 & 0 & --- \\
4.2 & 0.05 & 13.6 \\
10 & 0.16 & 4.4 \\
20 & 0.30 & 2.3 \\
25 & 0.36 & 1.9 \\
30 & 0.42 & 1.7 \\
\hline \hline
\end{tabular}

Table 3. Height mode instabilities evaluated.

\begin{tabular}{ccc}
\hline \hline \multicolumn{1}{c}{$\mathrm{C}_{\mathrm{D}_{\mathrm{v}}}$} & $\begin{array}{c}\text { Root location, } \\
\mathrm{rad} / \mathrm{sec}\end{array}$ & $\begin{array}{c}\text { Time to double } \\
\text { amplitude, sec }\end{array}$ \\
\hline 0.00001 & -0.01 & --- \\
-0.00003 & 0.02 & 40.8 \\
-0.00006 & 0.04 & 18.2 \\
-0.00008 & 0.05 & 13.6 \\
-0.00018 & 0.12 & 5.9 \\
-0.00024 & 0.16 & 4.4 \\
-0.00030 & 0.20 & 3.5 \\
\hline \hline
\end{tabular}

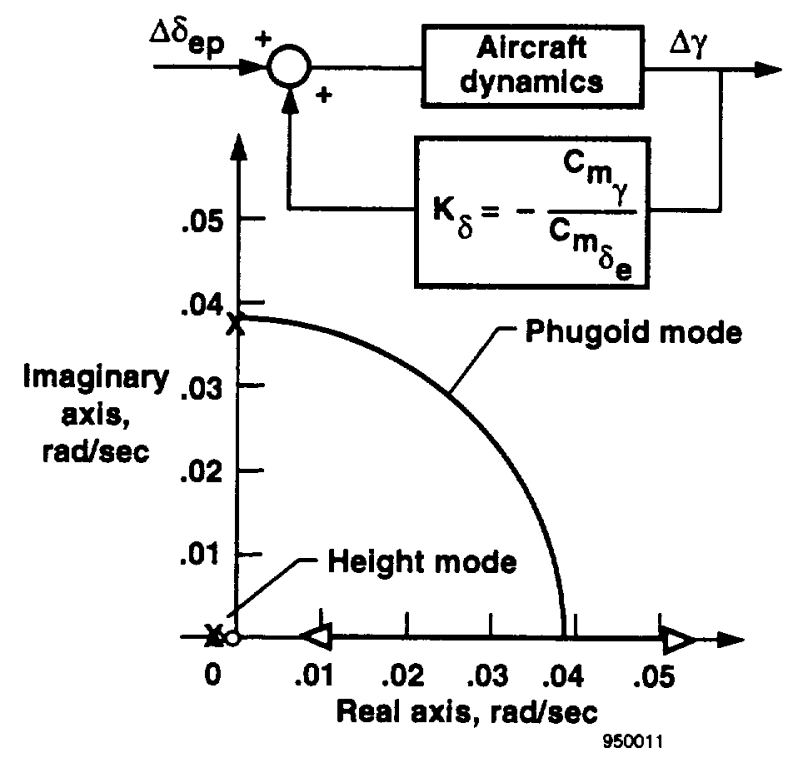

Figure 5. Aperiodic phugoid mode instability characteristics.

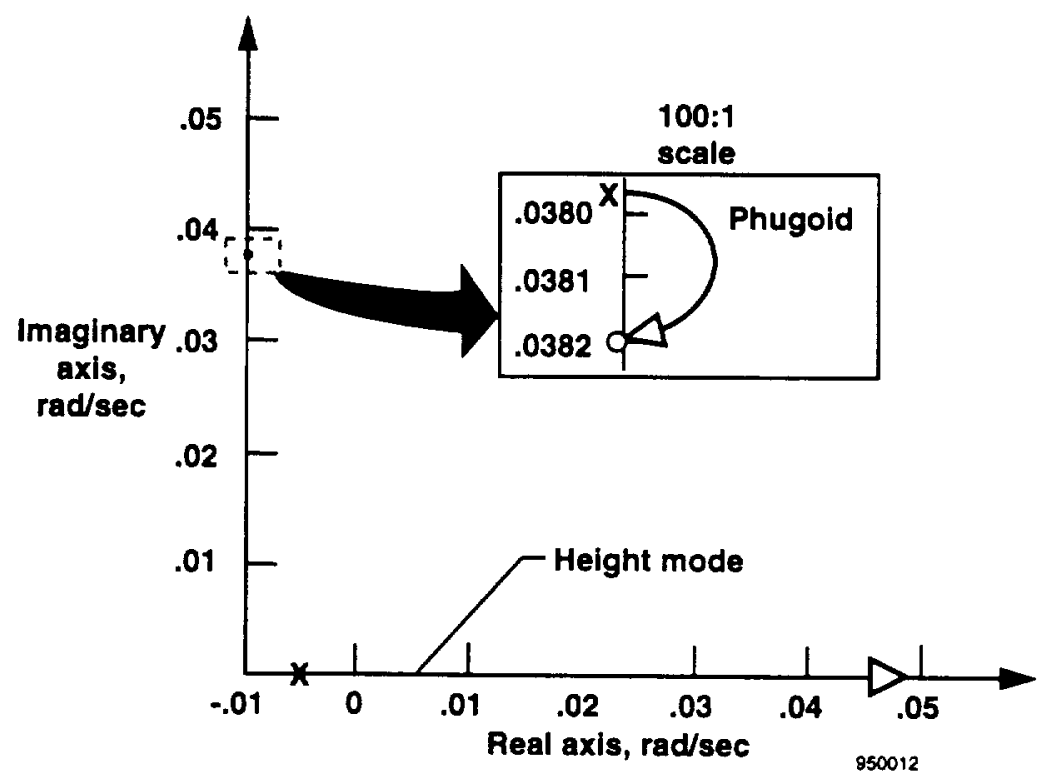

Figure 6. Aperiodic height mode instability root contours. 
To increase pilot workload, the test runs included atmospheric density perturbations for the pilot to fly through. The disturbances occurred within 1 to $20 \mathrm{sec}$ of each other in the shape of a cosine wave lasting $20 \mathrm{sec}$. The amplitude of the disturbance, whose sign was randomly modelled, was 2.5 percent of the standard density at an altitude of 110,000 $\mathrm{ft}$ and consistent with atmospheric variations observed from YF-12 flights. ${ }^{14}$

During some of the test runs, a secondary side task for the pilot was instituted to measure pilot workload. The method, called tapping, required the pilot to tap a button located on the stick as rhythmically as possible. The theory states that as the pilot workload increases, the irregularity of the tapping increases. A comparison between the regularity of the tapping for a given run (loaded tapping level, LTL) and the regularity of the tapping during straight and level flight with no disturbances (basic tapping level, BTL) yields a measure of the pilot workload or perceptual motor load (PML). The PML is calculated as follows:

$$
\text { PML }=(\mathrm{LTL}-\mathrm{BTL}) / \mathrm{BTL}
$$

Information on the tapping method as it was applied to this research has previously been given. ${ }^{10}$ General information on the tapping theory has also been reported previously. 15

\section{RESULTS AND DISCUSSION}

The following section discusses how phugoid and height mode instabilities affect Cooper-Harper ratings, compares the effects of workload and pilot performance on CooperHarper ratings, and analyzes pilot technique in controlling large instabilities. The effect of control power on
Cooper-Harper ratings is examined, and the tapping method is evaluated.

\section{Phugoid and Height Instability Impact on Cooper- Harper Ratings}

Figure 7 shows the Cooper-Harper ratings as a function of phugoid real-root locations without use of the tapping method. Five data points, generated by three pilots, were averaged at each instability. Eighty-three percent of the ratings fell within a \pm 1 pilot-rating band, illustrating the consistency of the results. The ratings stay relatively constant at low phugoid instabilities until a root location of $0.15 \mathrm{rad} / \mathrm{sec}$, where the ratings degrade sharply. Level $2 / 3$ and Level 3/Uncontrollable borders occur at unstable root locations of 0.23 and $0.44 \mathrm{rad} / \mathrm{sec}$ respectively, or 3 and $1.4 \mathrm{sec}$ time-to-double-amplitude respectively.

Figure 8 shows the nontapping Cooper-Harper ratings as a function of height mode instability. Seven data points, generated by four pilots, were averaged at each instability. Seventy-three percent of the ratings fell within $a \pm 1$ pilot-rating band, illustrating the consistency of the results. Similar to the phugoid data (fig. 7 ), relatively constant ratings occur for the low instabilities, degrading sharply as instability increases above a root location of approximately $0.015 \mathrm{rad} / \mathrm{sec}$. This result indicates a "cliff-like" characteristic in the height mode data. Comparing the slopes of the height mode and phugoid mode Cooper-Harper data (figs. 7 and 8) indicates that the "cliff" characteristic exists in the phugoid data to a lesser degree. Level $2 / 3$ and Level 3/Uncontrollable borders occur at unstable root locations of approximately 0.045 and $0.14 \mathrm{rad} / \mathrm{sec}$ respectively, corresponding to 15 and 5 sec time-to-double-amplitude.

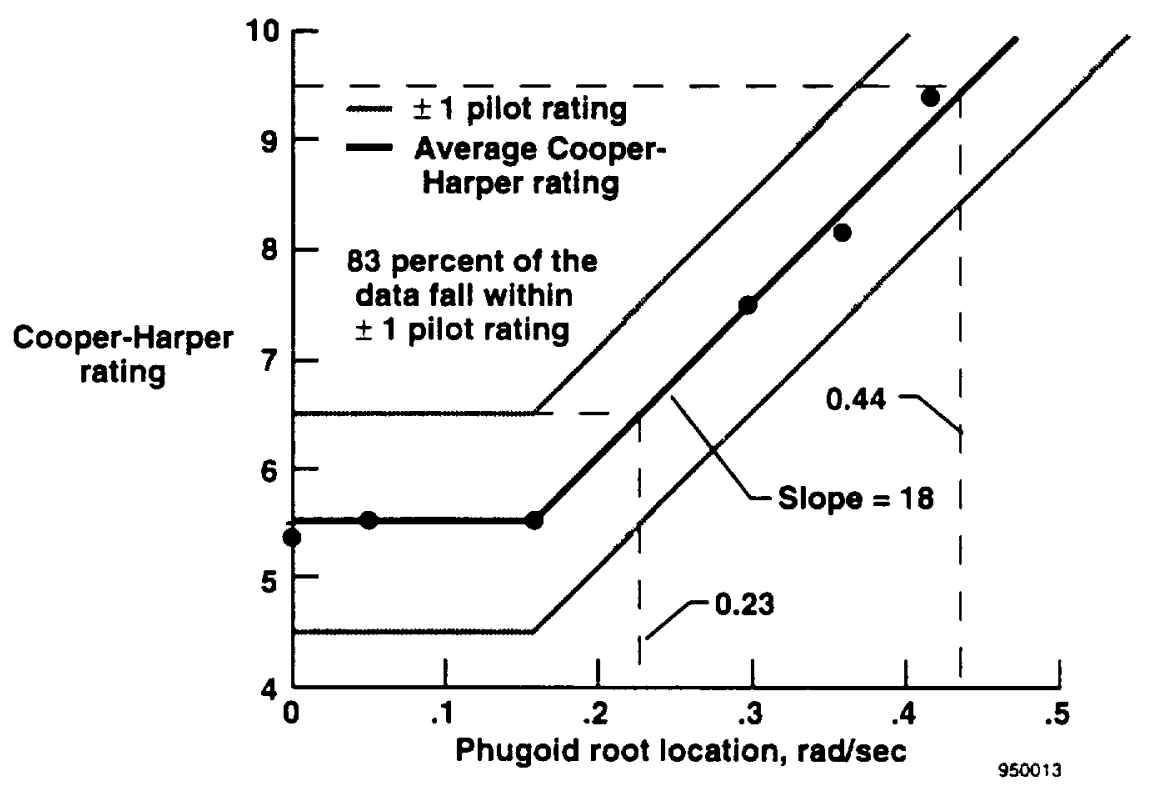

Figure 7. Average Cooper-Harper rating as a function of phugoid instability (nontapping data). 


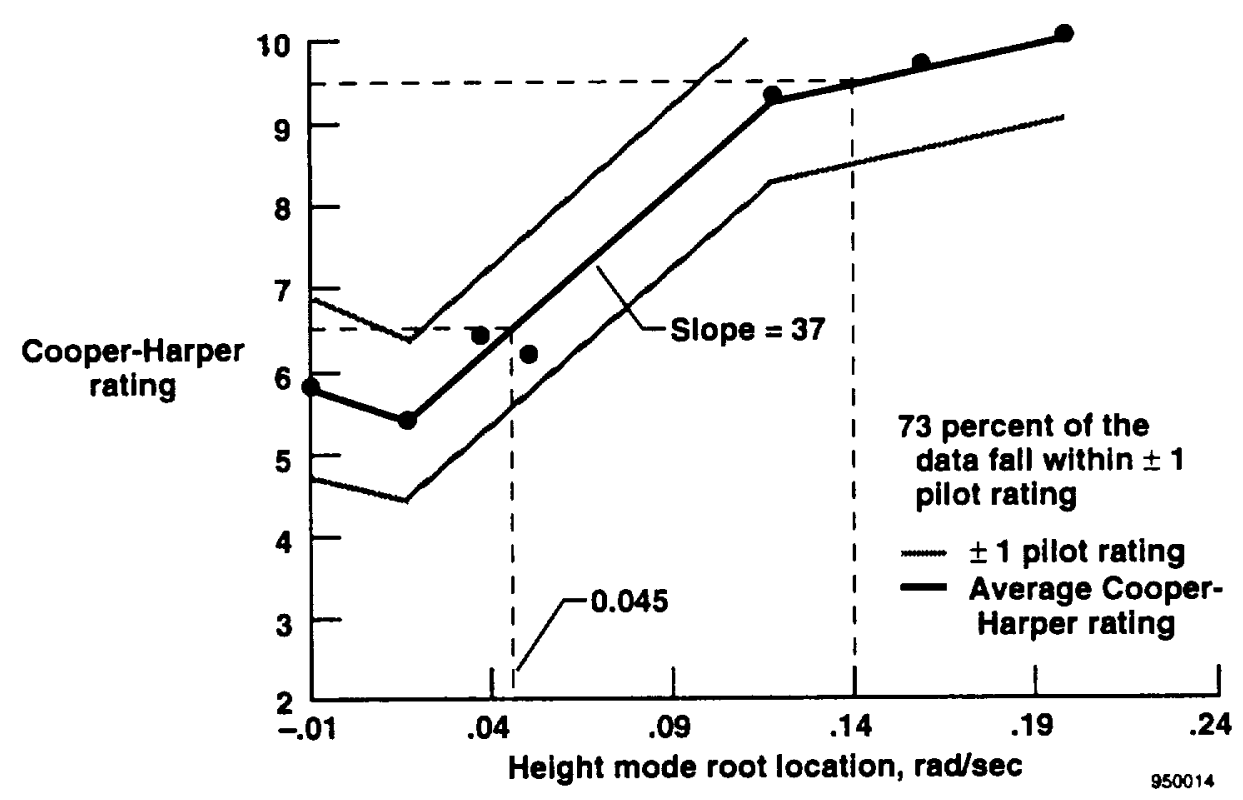

Figure 8. Average Cooper-Harper rating as a function of height mode instability (nontapping data).

Assuming Level 2 ratings are acceptable for backup control modes of hypersonic vehicles, these data indicate a time-to-double-amplitude of $15 \mathrm{sec}$ for the height mode and $3 \mathrm{sec}$ for the phugoid mode are acceptable limits. However, the apparent "cliff-like" tendencies in the ratings may warrant extra margin in design. Comparison of the phugoid and height mode data suggests the pilot is more sensitive to the height mode instability than the phugoid mode instability, as the height mode borders occur at larger time-to-double-amplitudes. This result might be expected because the height mode produces a divergence in energy as well as flightpath, thus requiring both throttle and pitch control to correct a deviation. The phugoid mode, on the other hand, is primarily a constant energy mode and deviation can be corrected with the pitch controller alone.

\section{Comparison of Workload and Performance Effects on Cooper-Harper Ratings}

In the previous section, all of the evaluations included both controllable and uncontrollable cases. In this section, the comparison of performance measures and corresponding pilot ratings includes only the controllable cases because the performance was calculated only for those cases.

The trends in the Cooper-Harper rating data and the workload rating data for the controllable phugoid instabilities without tapping (fig. 9) are similar. Both CooperHarper and workload ratings start out relatively flat and then degrade after a root location of $0.16 \mathrm{rad} / \mathrm{sec}$. Comparison of Cooper-Harper and workload ratings for the height mode (fig. 10) shows similar results. The reduced Cooper-Harper rating of 7 at the height root location of $0.15 \mathrm{rad} / \mathrm{sec}$ was the only controllable run of the 7 test runs and therefore does not represent a meaningful statistical average. These results suggest that pilot workload was the primary consideration driving the Cooper-Harper rating. However, a question about the influence of pilot performance on Cooper-Harper ratings remains.

Figure 11 shows the pilot's performance, displayed as a percentage of desired performance, as a function of phugoid instability. The pilot performance on speed stays relatively flat until a root location of $0.3 \mathrm{rad} / \mathrm{sec}$ and then degrades, similar to the Cooper-Harper and workload ratings. However, the degradation in speed performance becomes no worse than approximately desired speed at the most unstable phugoid tested. The altitude performance data show some degradation as the instability increases but remains relatively flat and well within desired performance. Figure 9 shows even at the highest root locations of approximately $0.4 \mathrm{rad} / \mathrm{sec}$, where control is marginal (Cooper-Harper ratings of 8-9), the performance data (fig. 11) remain approximately less than or equal to desired performance. Therefore, despite some degradation in performance in speed, the pilots achieved levels of performance within the desired range even as the ratings deteriorated to the point of uncontrollability.

Figure 12 shows the pilot's performance, displayed as a percentage of desired performance, as a function of controllable height instability. Similar to the phugoid case, the pilots maintained desired performance on speed and altitude despite the degradation of Cooper-Harper ratings to 9 (fig. 10). 


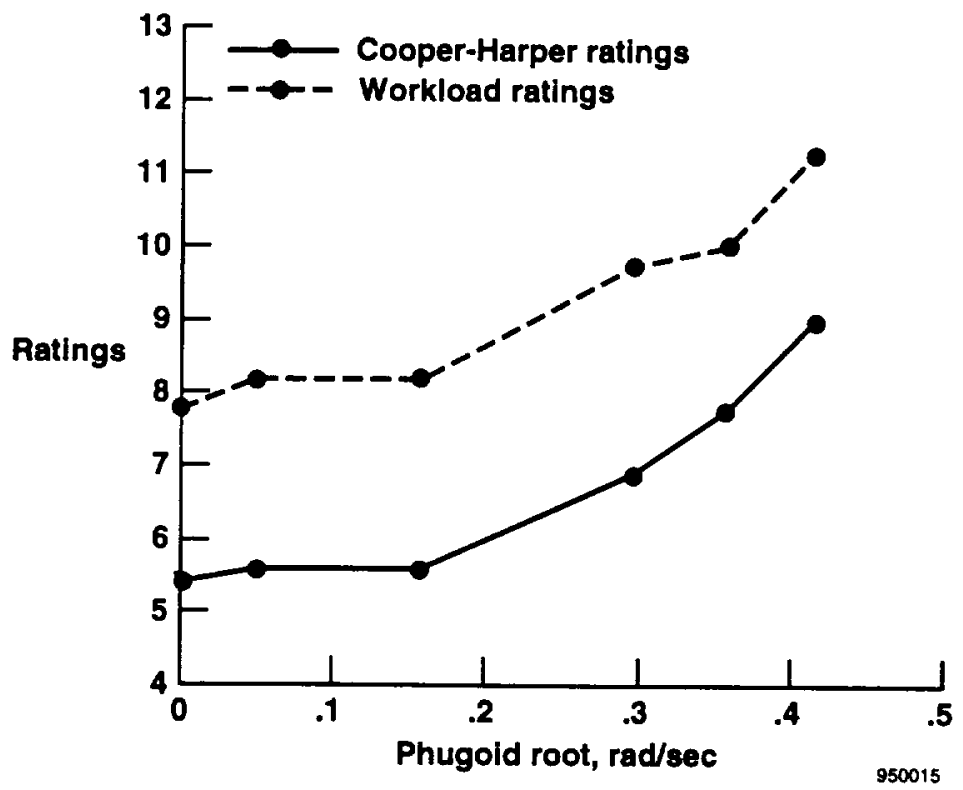

Figure 9. Average Cooper-Harper and workload ratings of the controllable cases as a function of phugoid instability (nontapping data).

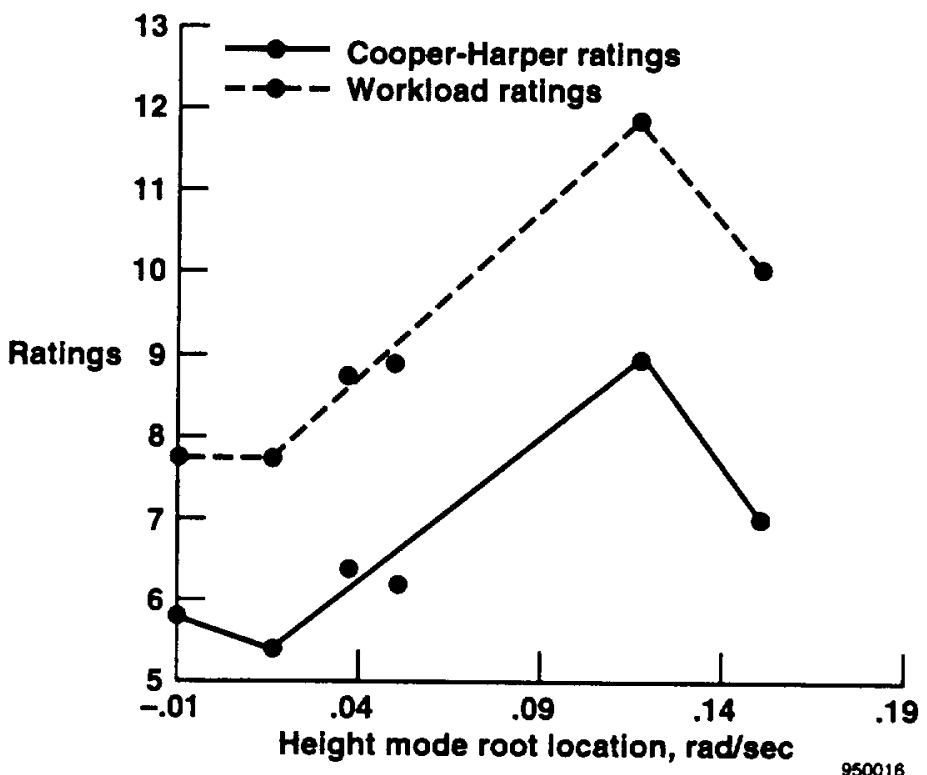

Figure 10. Average Cooper-Harper and workload ratings of the controllable cases as a function of height instability (nontapping data). 


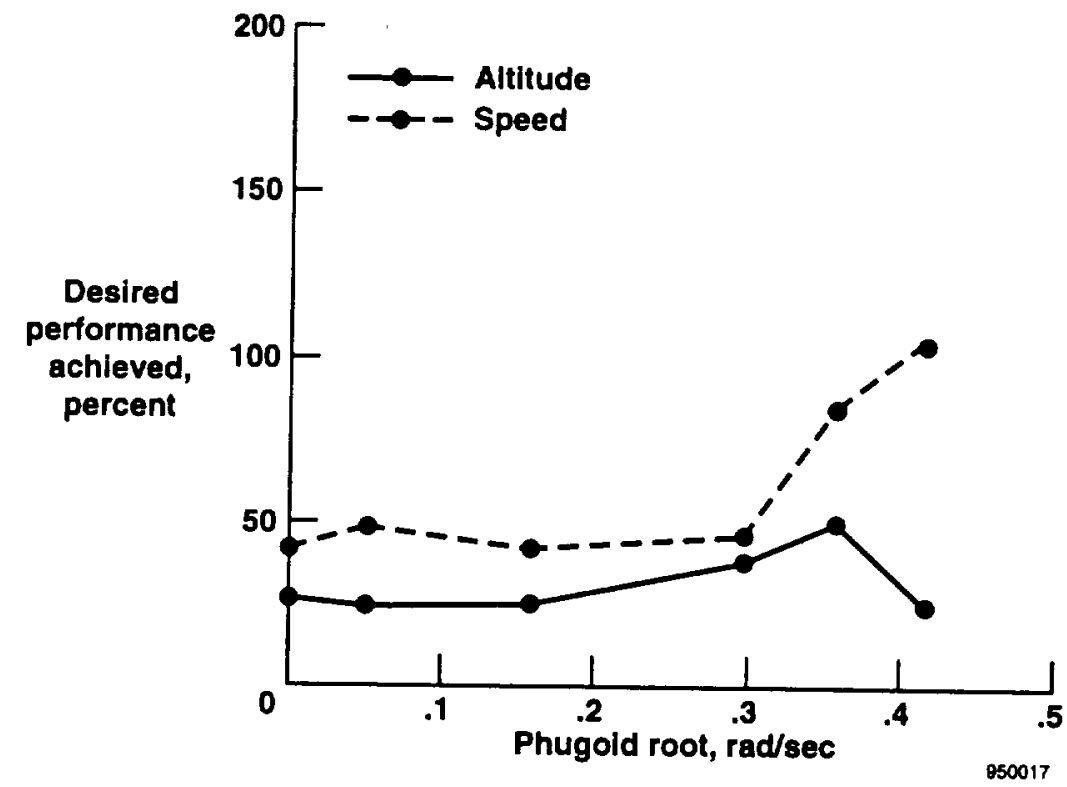

Figure 11. Percentage of desired performance achieved by the pilot for nontapping, phugoid mode data.

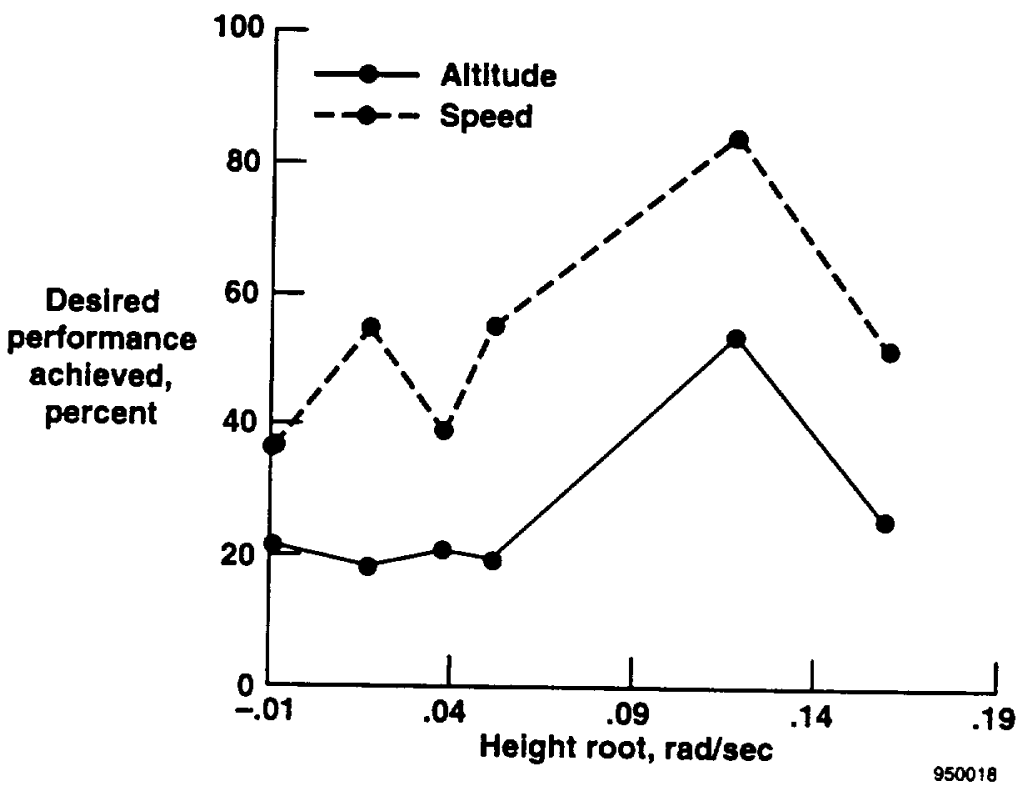

Figure 12. Percentage of desired performance achieved by the pilot for nontapping height mode data.

The obvious conclusion is that pilot workload and not pilot performance is the major influence on CooperHarper rating. This result implies that a pilot flying aircraft with these unstable modes can achieve an acceptable level of performance, but the workload required to achieve this level of performance increases dramatically with instability. In measuring the flying qualities impact of these modes, a measure of workload is necessary.

Figures 11 and 12 show that the speed performance was more critical than the altitude performance. With phugoid roots greater than $0.3 \mathrm{rad} / \mathrm{sec}$, the speed performance degraded, whereas the altitude performance remained flat. Also, pilots achieved a lower percentage of altitude deviation than speed deviation across all instabilities. This lower percentage of altitude deviation may be influenced by the fact that equivalent airspeed is more difficult to control because it is a function of Mach and altitude. The choice of desired airspeed performance of \pm 5 knots equivalent airspeed ( $18 \mathrm{lbs} / \mathrm{ft}^{2}$ dynamic pressure) may also be an influence. Tight performance on speed was chosen because of the sensitivity of the propulsion systems to 
dynamic pressure and because tight control of dynamic pressure is critical to the success of a single-stage-to-orbit vehicle mission.

\section{Analysis of Pilot Technique for Large Instabilities}

In general, the data presented show that pilots can successfully control aircraft models with quite large phugoid and height mode instabilities. For example, phugoid instabilities with a time-to-double-amplitude of $1.7 \mathrm{sec}$ were at times controllable, although the workload was very high. Inherent to the design of air-breathing hypersonic vehicles is the shaping of the aft fuselage to act as a nozzle. This design creates significant coupling between the vertical and longitudinal axes when the thrust is modulated. Figure 13 shows this principle with the linearized version of the GHAME at Mach 10. A positive amplitude throttle step produces a significant increase in vertical and longitudinal speed. This coupling characteristic is potentially quite useful to the pilot in controlling large instabilities. The following evaluation of the data determines whether or not the pilot took advantage of this coupling characteristic.

Figure 14 shows the time history of a run split into three regions, $A, B$, and $C$, to show how one pilot controlled a phugoid instability with a time-to-double-amplitude of $1.7 \mathrm{sec}$. At the beginning of region $A$, the pilot observed the negative trend on vertical speed and reacted with full positive aft stick deflection, thereby reducing the slope of the vertical speed but not negating it. At this point, the pilot would have lost control of the vehicle unless
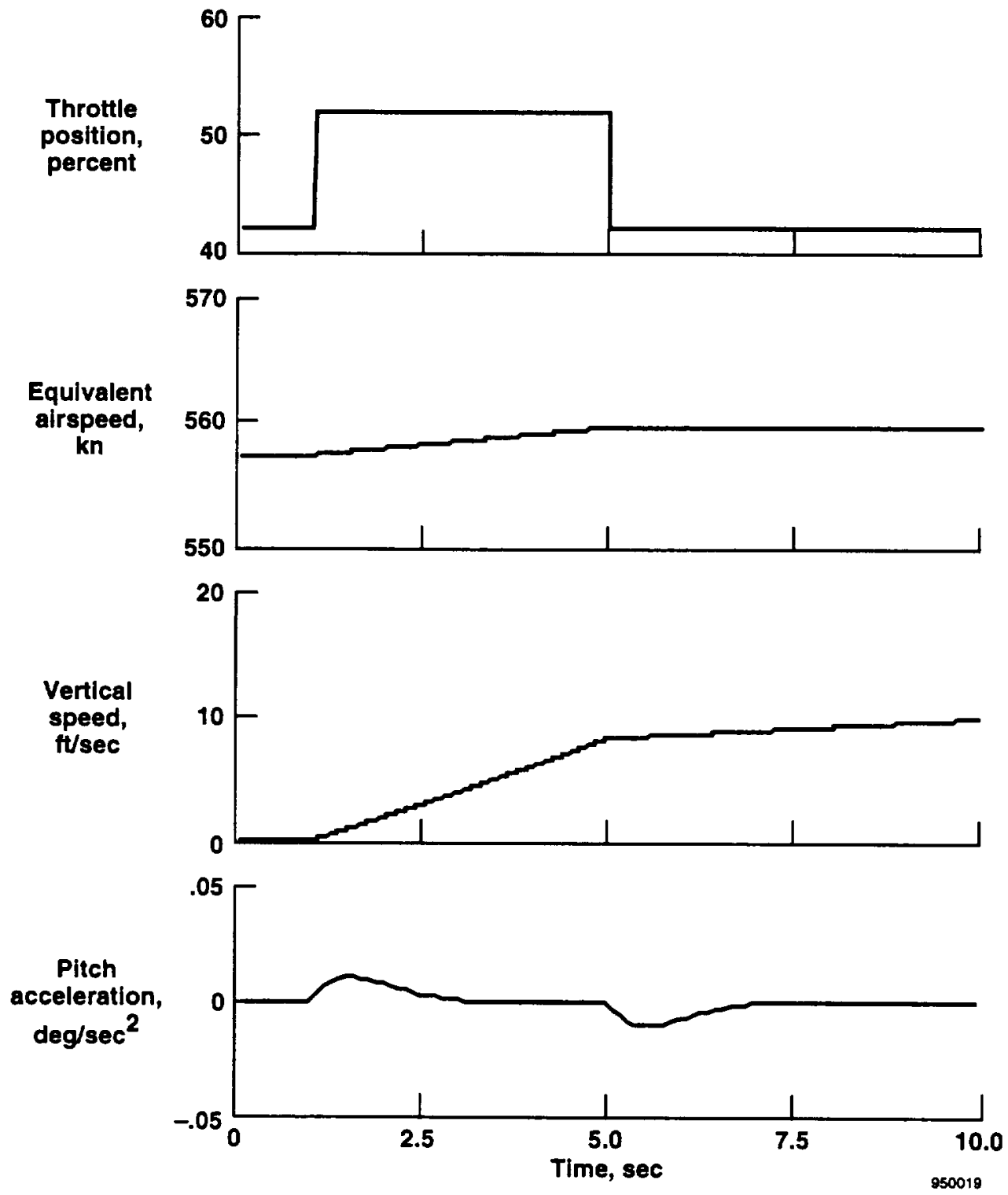

Figure 13. Throttle step showing vertical speed and longitudinal speed coupling. 

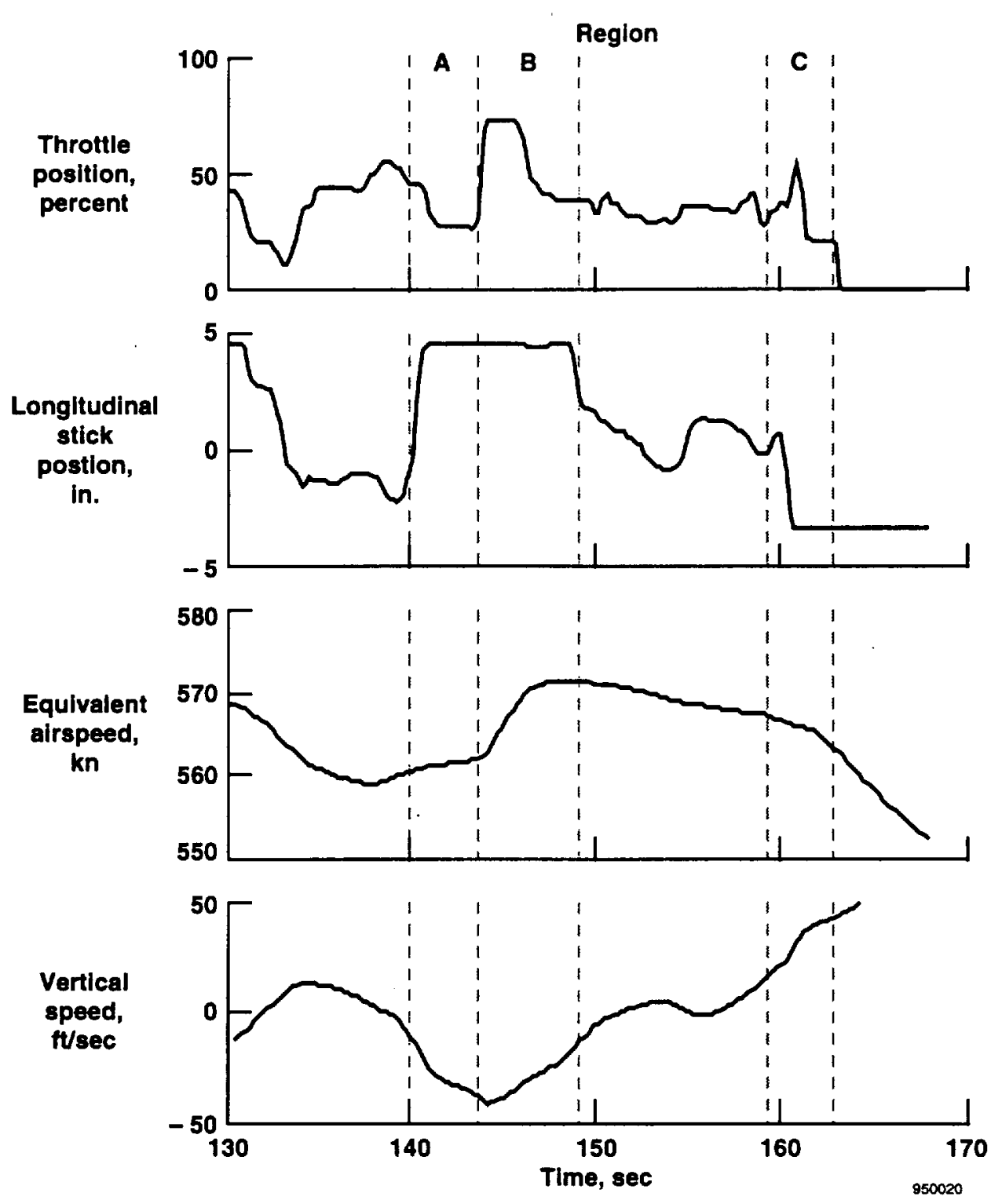

Figure 14. Pilot technique controlling phugoid mode instability.

something else was done to arrest the vertical speed. Region B shows the pilot's reaction. The pilot increased the throttle sharply at the beginning of region $B$, thereby creating enough positive vertical speed to negate the downward trend. Once the pilot observed the sign reversal of the vertical speed, the pilot sharply decreased the throttle.

At the end of region B, the pilot was confident control was retained and thus reduced the stick deflection off its limit. However, the vertical speed kept climbing positively and went unnoticed until approximately $160 \mathrm{sec}$, which is the beginning of region $C$. At this point, the pilot reversed the above procedure by reducing the stick deflection. Again, it was not enough to arrest the trend of the vertical speed, so the pilot applied a negative, sharp throttle increment. Unfortunately, the throttle input was too late and the pilot lost control.

Nevertheless, Figure 14 shows the pilot used sharp throttle inputs to take advantage of the coupling between longitudinal and vertical axes to control a vehicle otherwise uncontrollable. This technique with the throttle, a "bang-bang" technique, increased controllability and minimized airspeed deviations. Note that the engine model for this simulator experiment was a simple, linear model with no time delay. A more realistic engine modeled with filters or time delays would reduce the effectiveness of this "bang-bang" technique. 


\section{Effect of Control Power on Flying Qualities}

Because the maximum lift coefficient was not exceeded, the inability to control vertical speed with full aft stick deflection (fig. 14) implies the pilot ran out of control power. However, the pilot supplemented the control power with the coupling of thrust between the vertical and longitudinal axes. The success of this technique implies the pilot was not limited by the capacity to handle the large instabilities, but rather by the available control power. If this implication is true, increasing the control power would allow the pilot to fly aircraft models with even higher instabilities.

Figure 15 shows the impact of modifying the control power on one pilot's Cooper-Harper ratings of phugoid instabilities. By varying the control surface deflection limits, three different control power variations are compared: the baseline control power, 0.5 of the baseline control power, and 1.5 of the baseline control power. The pilot controlled much higher levels of phugoid instability with the increased control power, as evidenced by the increase in the Level $2 / 3$ border from root locations of 0.23 to $0.32 \mathrm{rad} / \mathrm{sec}$ and Level $3 /$ Uncontrollable border from root locations of 0.44 to $0.60 \mathrm{rad} / \mathrm{sec}$.

These data indicate that the long-term modes are flyable, even for large instabilities, as long as enough control power is available. As the available control power lessens, the bandwidth required increases and the workload necessary to maintain acceptable or controllable performance increases, resulting in an increase in Cooper-Harper and workload ratings.

Figure 16 shows this relationship by plotting the vertical speed response of two phugoid instabilities to a step input

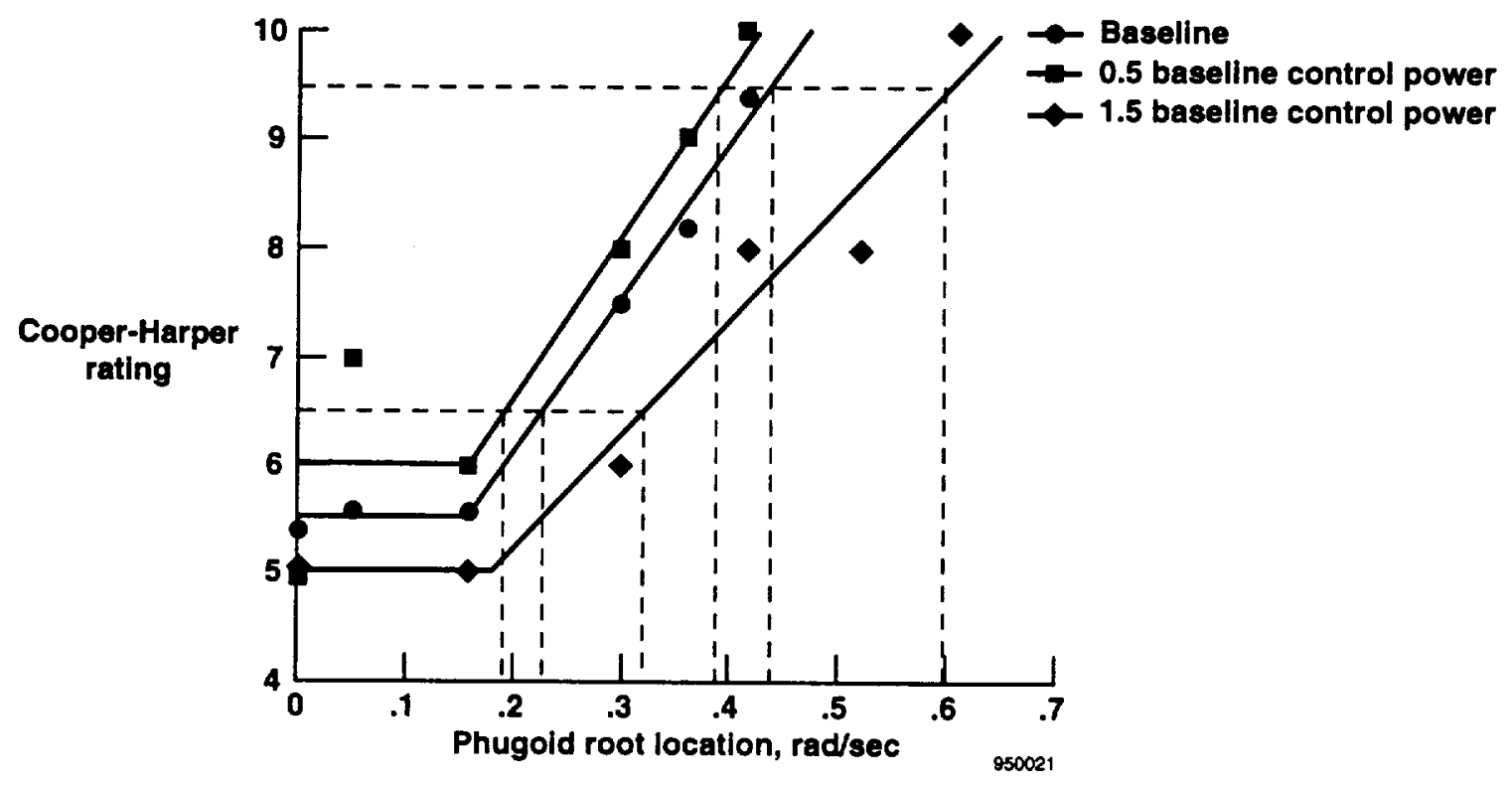

Figure 15. Effects of available control power on Cooper-Harper pilot ratings of phugoid mode instabilities.

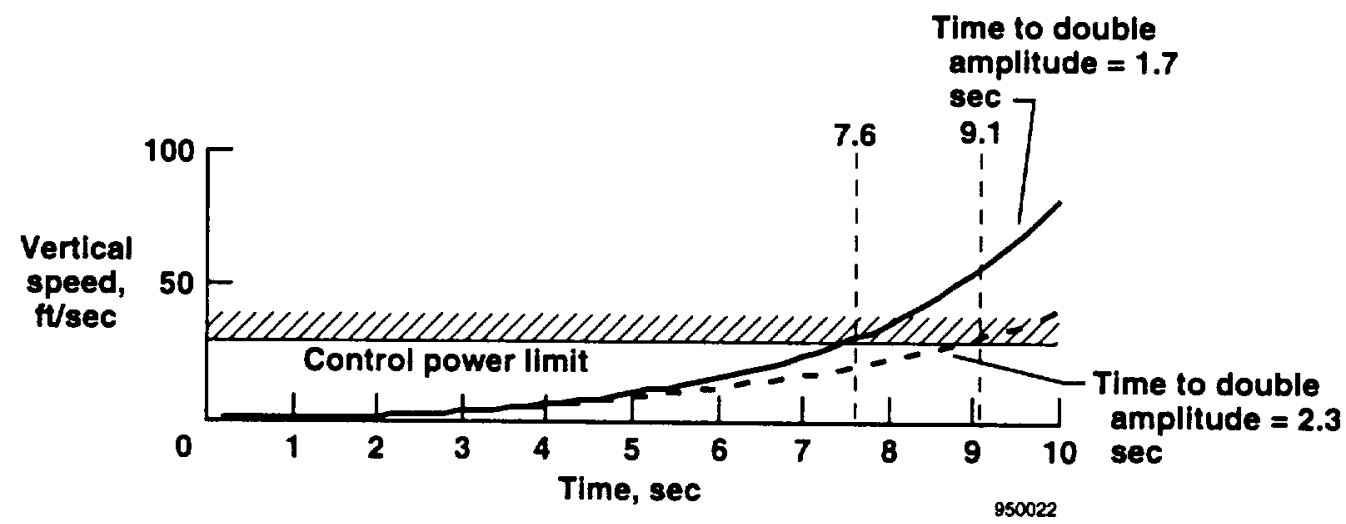

Figure 16. Effects of control power on pilot workload requirements. 
of stick deflection and the vertical speed control power limit, which is the point where full reversed stick deflection just arrests the vertical speed. Decreasing the time-to-doubleamplitude reduces the reaction time necessary for the pilot to maintain controllability, thereby increasing the concentration and effort required of the pilot. Decreasing the control power available, which is equivalent to lowering the "control power limit" boundary (fig. 16), has the same effect. Therefore, the relationship between the unstable phugoid mode and the control power available impacts the flying qualities of a hypersonic vehicle and may influence the control power requirements of the design.

Not only could this hypothesis explain why the CooperHarper ratings were primarily a function of the workload rating, as discussed earlier; it also could explain the "clifflike" ratings. For low levels of instabilities, the bandwidth required is low enough not to influence the pilot ratings. As the instability increases, or as the control power decreases, the bandwidth required begins to approach the maximum available from the pilot-vehicle system, resulting in deteriorated ratings.

\section{Tapping Method Evaluation}

As stated earlier, the main objective of the tapping task was to measure the degree of PML, or workload, on the pilot as the instabilities increased. Since tapping was designed as a secondary task, no degradation in pilot ratings should occur in the main task because of tapping. Figures 17 and 18

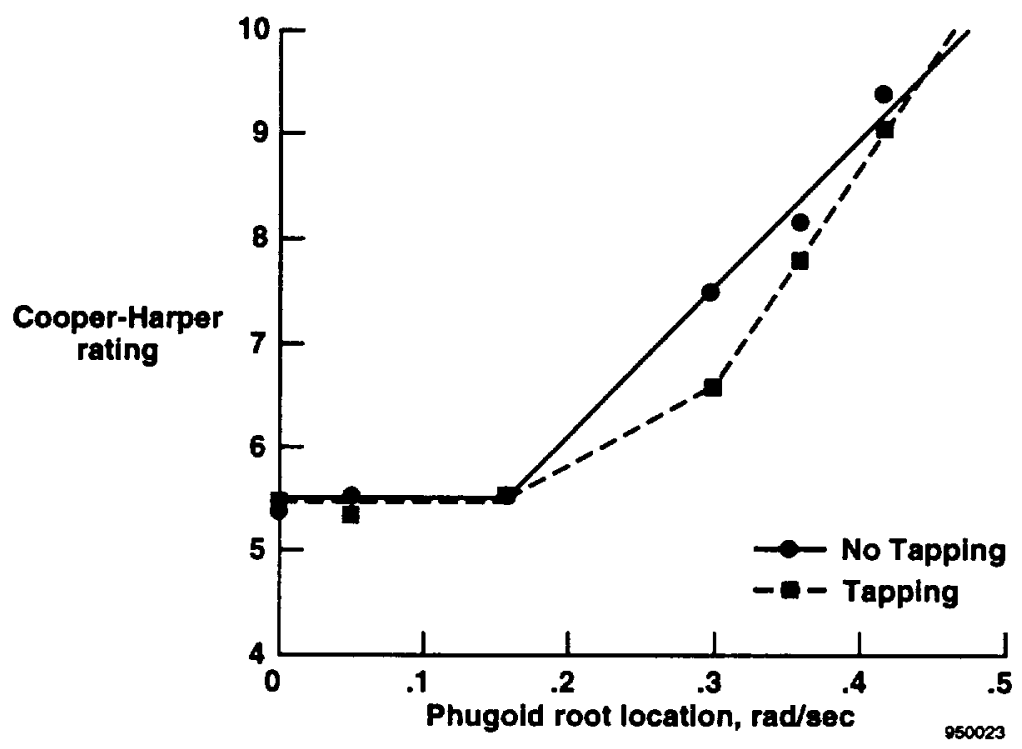

Figure 17. Average Cooper-Harper ratings of tapping and nontapping data as a function of phugoid instability

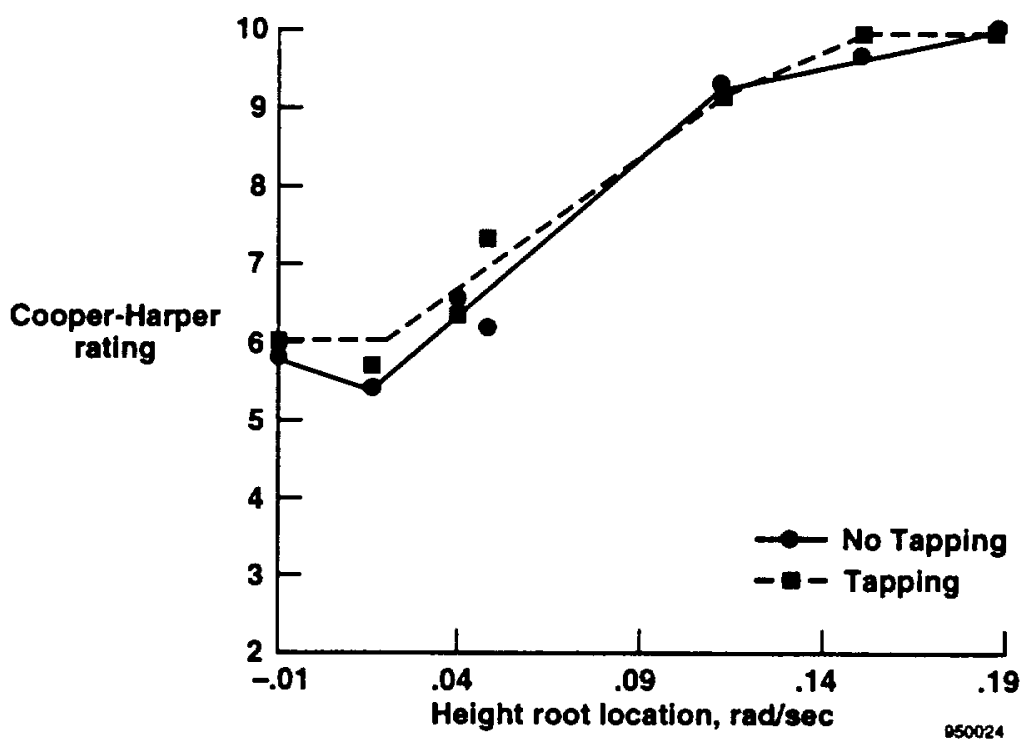

Figure 18. Average Cooper-Harper ratings of tapping and nontapping data as a function of height mode instability. 
compare tapping and nontapping Cooper-Harper ratings as a function of the phugoid and height mode instability levels respectively. Except for the rating at a real phugoid root of approximately $0.3 \mathrm{rad} / \mathrm{sec}$ (fig. 17), the ratings show little difference between tapping and nontapping data. From this observation, it can be concluded the secondary task did not interfere with the main task.

But the question on how well the tapping estimated pilot workload remains. Figure 19 shows the average of the pilot's estimation of workload with tapping for the phugoid and height mode instabilities. As the phugoid instability increases, the workload stays relatively constant at first and then degrades sharply at a root location of approximately $0.3 \mathrm{rad} / \mathrm{sec}$. The workload for increasing height mode instabilities exhibits a similar trend, degrading at a root location of $0.024 \mathrm{rad} / \mathrm{sec}$. These observations match intuition as well, as one would expect workload to increase with increasing instability.

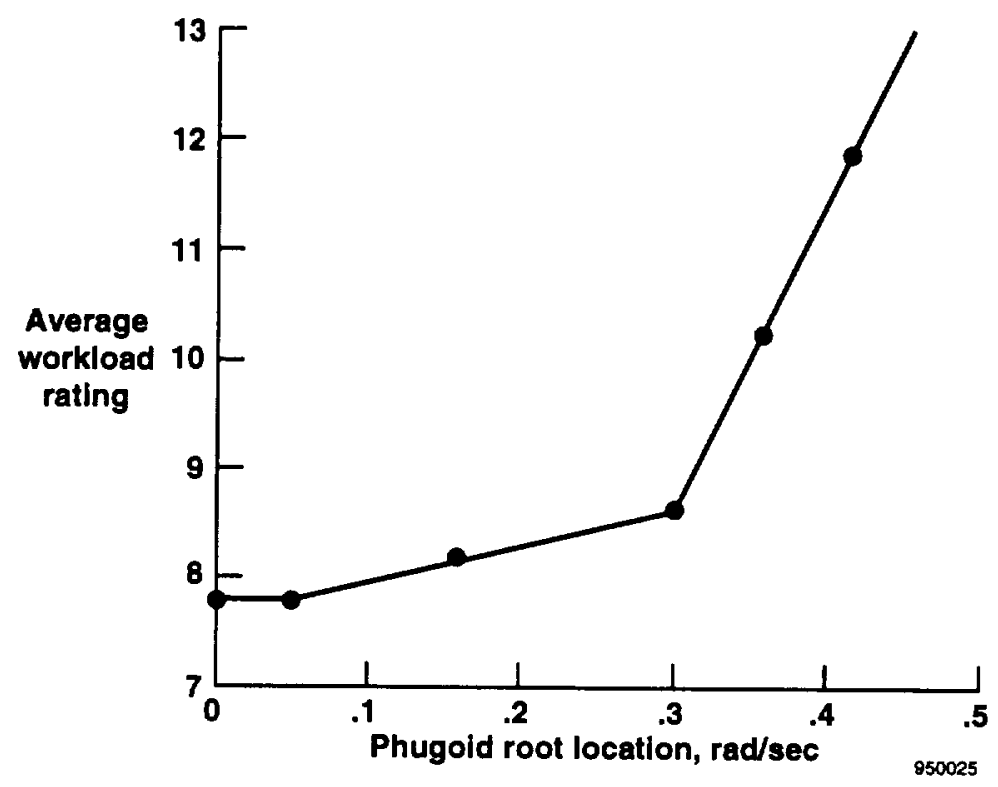

(a) Phugoid mode data.

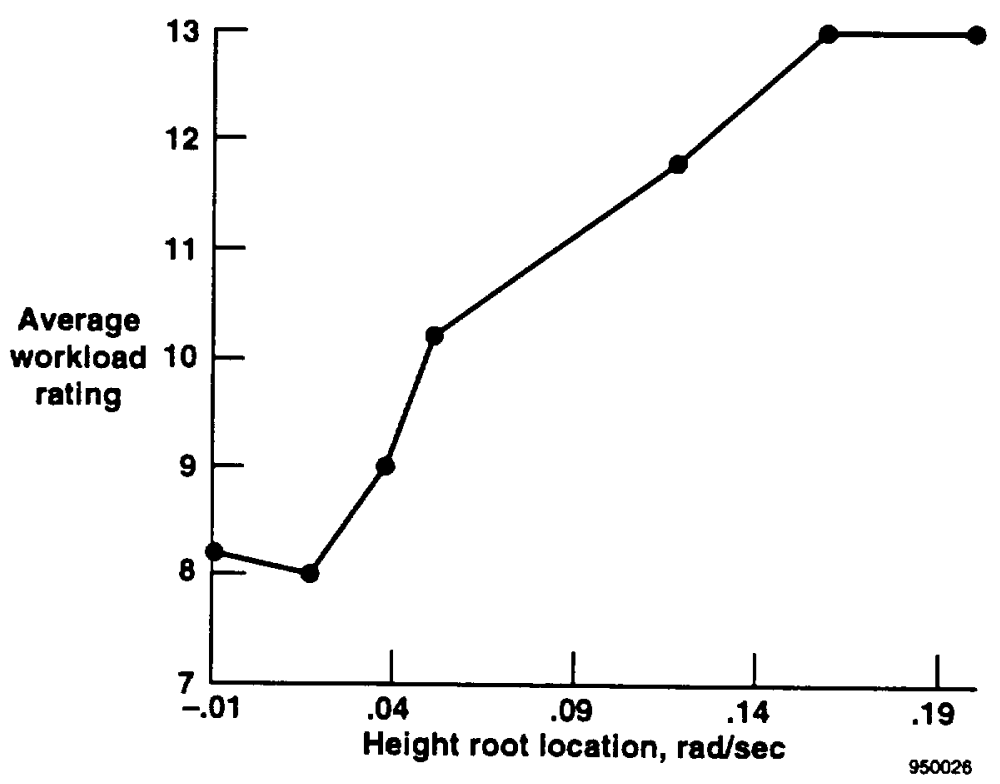

(b) Height mode data.

Figure 19. Average workload scale ratings as a function of height and phugoid instabilities (tapping data). 
Figure 20 shows all PML data as a function of phugoid and height mode instabilities and overplots the average PML at each instability. The phugoid data (fig. 20(a)) shows an increase in PML after the root location of 0.3 $\mathrm{rad} / \mathrm{sec}$, which was the point where the average pilot workload rating began degrading sharply. Nevertheless, the scatter in the PML data, which is as large as the previously noted increase in PML, obscures any trends exhibited by averaged PML data and prevents the conclusion that any significant correlation exists between increasing instability and PML.

In addition, no correlation between PML and increasing instability is observed in the height mode data (fig. 20(b)) because the large degree of scatter in PML obscures any trends exhibited by the averaged PML data. Although consistent trends between PML and instability exist in some individual series of runs, these trends exhibit both

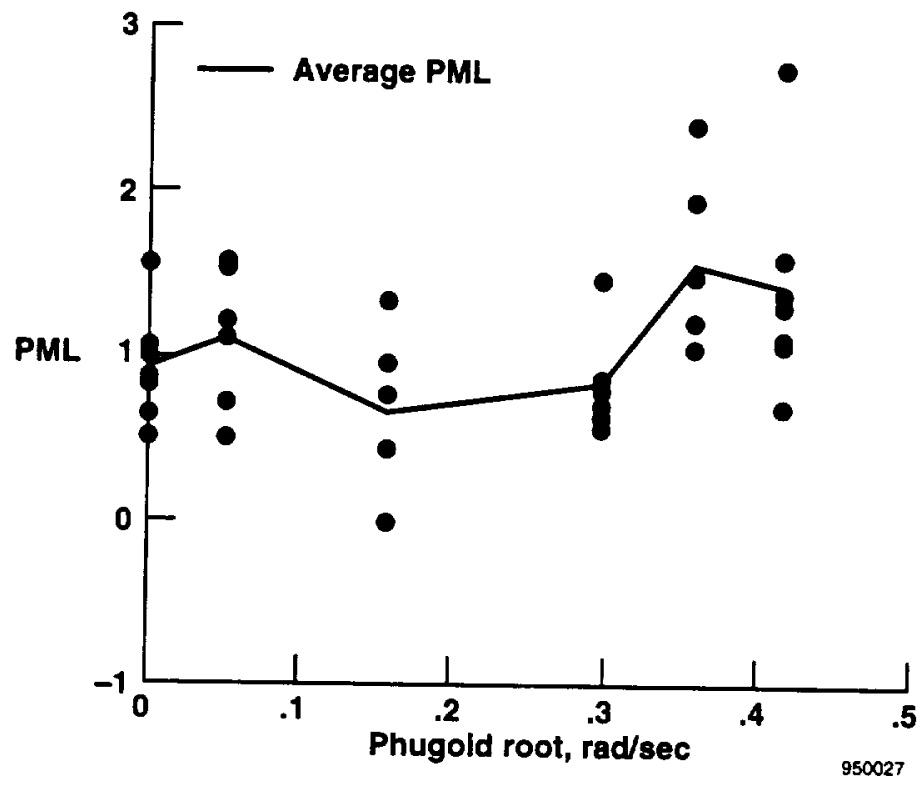

(a) Phugoid mode data.

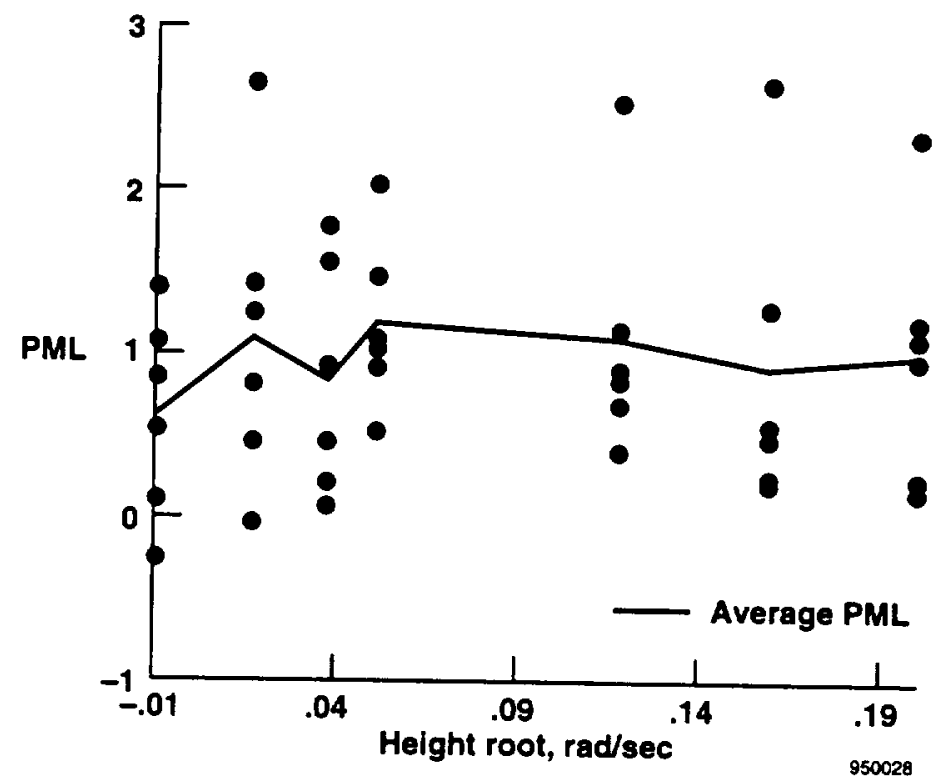

(b) Height mode data.

Figure 20. Perceptual motor load as a function of instability for height and phugoid mode data. 
increasing and decreasing PML as a function of increasing instability. The lack of correlation between phugoid and height mode instabilities and PML is inconsistent with the pilot's estimation of workload (fig. 19). The pilot's estimation shows a strong correlation between workload and increasing instability.

In some series of runs, PML increased as the number of the runs evaluated in the series increased. After the pilots evaluated a few runs in a series, they occasionally complained that their fingers became tired because of the tapping. This effect could increase the irregularity of their tapping and produce increasing PML with the number of the runs evaluated in the series. This factor may indicate pilot fatigue is sometimes a more significant factor in the tapping workload measurement than the increasing instability. However, data from previous research ${ }^{15}$ show no indication of degradation caused by fatigue in test runs of comparable length in time. No conclusive correlations were observed when the data were evaluated for individual pilots.

For this experiment, the tapping method was inconsistent in measuring pilot workload. No reason for the inconsistency has been isolated to date because the various effects could not be separated out with certainty.

\section{SUMMARY}

The NASA Dryden Flight Research Center and the Technical University of Munich are cooperating to research the flying qualities impact of unstable long-term dynamics on planes in hypersonic flight. These issues were investigated with a dedicated flight simulator for hypersonic vehicles located at NASA Dryden. The results presented in this paper are as follows:

1. Level 2 handling qualities could be maintained to a time-to-double-amplitude of $15 \mathrm{sec}$ for the height mode and $3 \mathrm{sec}$ for the phugoid mode. Level 2 is appropriate for the design of a manual backup control mode; however, the trends in the ratings indicated "cliff-like" tendencies that may warrant extra margin in design. The borders of controllability were a timeto-double-amplitude of $5 \mathrm{sec}$ for the height mode and $1.4 \mathrm{sec}$ for the phugoid mode. A technique developed by the pilots to take advantage of the coupling of thrust between the vertical and longitudinal axes allowed these large instabilities to be flyable.

2. The pilots were able to maintain a steady level turn at or within desired performance margins even at the highest levels of instabilities, but at a high cost of workload, as reflected by the increased Cooper-Harper ratings.
3. The flying qualities impact from the long-term dynamics influence control power design requirements. The influence is shown by the deterioration of the Cooper-Harper ratings that accompanies decreasing available control power. As instability increases, the bandwidth required approaches the bandwidth the pilot is capable of producing with the aircraft. At this point, workload and Cooper-Harper ratings deteriorated. Decreasing control power has a similar effect.

4. A method for measuring pilot workload, the tapping method, did not work as shown by the inconsistent results for these experiments.

\section{REFERENCES}

${ }^{1}$ Lötzerich, K., "Comparative Assessment of Future Aerospace Planes," AIAA-93-5014, Nov. 1993.

\footnotetext{
2Berry, Donald T., National Aero-Space Plane Flying Qualities Requirements, NASP TM-1084, 1989.
}

${ }^{3}$ U.S. Department of Defense, "Flying Qualities of Piloted Vehicles,” MIL-STD-1797, Mar. 1987.

${ }^{4}$ Sachs, Gottfried, "Flying Qualities Problems of Aerospace Craft," AIAA-90-2804, Aug. 1990.

5Berry, Donald T., "Longitudinal Long-Period Dynamics of Aerospace Craft," AIAA-88-4358, Aug. 1988.

${ }^{6}$ Etkin, Bernard, "Longitudinal Dynamics of a Lifting Vehicle in Orbital Flight," Journal of the Aerospace Sciences, Vol. 28, 1961, pp. 779-788, 832.

${ }^{7}$ Sachs, G., Knoll, A., Stich, R., and Cox, T., "Flugeigenschaftsuntersuchungen mit dem HyperschallFlugsimulator der NASA," DGLR Jahrbuch 1993 I, Sep. 1993, s. 77-83.

${ }^{8}$ Sachs, G., Knoll, A., Stich, R., and Cox, T., "Simulations- und Flugversuche über Flugeigenschaften von $\mathrm{Hy}$ perschall-Flugzeugen," Zeitschrift für Flugwissen-schaften und Weltraumforschung, Band 19, Heft 1, Feb. 1995.

${ }^{9}$ Sachs, G., Knoll, A., Stich, R., and Cox, T., "Hypersonic Simulator Experiments for Long-Term Dynamics Flying Qualities," AIAA-93-5088, Nov. 1993.

${ }^{10}$ Sachs, G., Knoll, A., Stich, R., and Cox, T., "Simulator and Flight Tests on Aerospace Plane Long-Period Control and Flying Qualities," ALAA-94-3508, Aug. 1994.

${ }^{11}$ Berry, Donald T., National Aerospace Plane Flying Qualities Task Definition Study, NASP TM-100452, 1988. 
${ }^{12}$ Grantham, William D., Nguyen, Luat T., Neubauer, M.J., Jr., and Smith, Paul M., "Simulator Study of the LowSpeed Handling Qualities of a Supersonic Cruise ArrowWing Transport Configuration During Approach and Landing," Proceedings of the SCAR Conference, NASA CP-001, Nov. 1976.

${ }^{13}$ Cooper, George E., and Harper, Robert P., Jr., The Use of Pilot Rating in the Evaluation of Aircraft Handling Qualities, NASA TN-D-5153, 1969.
${ }^{14}$ Berry, Donald T., and Gilyard, Glenn B., "Airframe/Propulsion System Interactions-An Important Factor in Supersonic Aircraft Flight Control," AIAA-73-831, Aug. 1973.

${ }^{15}$ Michon, J. A., "Tapping Regularity as a Measure of Perceptual Motor Load," Ergonomics, Vol. 9, No. 5, 1966, pp. 401-412. 


\section{Appendix}

\section{LINEAR EQUATIONS AT MACH 10 AND AN ALTITUDE OF 110,000 FEET}

This appendix describes the linear equations of motion that were used in the flying qualities experiment. Basic aircraft equations and control system block diagrams are presented for both longitudinal and lateral-directional axes.

\section{LONGITUDINAL EQUATIONS}

Figure A-1 shows the longitudinal block diagram. Pilot inputs into the control system are represented as longitudinal stick deflection, $\delta_{e p}$, and throttle position, $\delta_{T}$. The linear aircraft equations of motion are represented by the state-space equation, which is defined as follows:

$$
\begin{aligned}
& A=\left|\begin{array}{ccccc}
-0.06 & 1 & -0.53 \times 10^{-6} & 0.12 \times 10^{-6} & 0.25 \times 10^{-8} \\
-4.0 & -0.11 & 0.12 \times 10^{-7} & -0.24 \times 10^{-8} & 0.17 \times 10^{-5} \\
-34.5 & 0.13 \times 10^{-3} & \mathrm{X} & 0.28 \times 10^{-5} & -26.42 \\
-0.10 \times 10^{5} & 0.70 \times 10^{-2} & 0.61 \times 10^{-5} & 0.12 \times 10^{-5} & 0.10 \times 10^{5} \\
0 & 1 & 0.48 \times 10^{-7} & -0.23 \times 10^{-10} & 0.17 \times 10^{-8}
\end{array}\right| \\
& \mathrm{B}=\left|\begin{array}{cc}
-0.75 \times 10^{-3} & -0.19 \times 10^{-5} \\
-1.34 & 0 \\
0.21 \times 10^{-4} & 1 \\
0 & 0 \\
0 & 0
\end{array}\right| \mathrm{x}=\left|\begin{array}{c}
\alpha \\
q \\
V \\
H \\
\theta
\end{array}\right| \quad \mathrm{u}=\mid \begin{array}{c}
\delta_{e} \\
\delta_{T}
\end{array} \\
& \mathrm{C}=\left|\begin{array}{ccccc}
57.3 & 0 & 0 & 0 & 0 \\
0 & 57.3 & 0 & 0 & 0 \\
0 & 0 & 1 & 0 & 0 \\
0 & 0 & 0 & 1 & 0 \\
0 & 0 & 0 & 0 & 57.3 \\
-57.3 & 0 & 0 & 0 & 57.3
\end{array}\right|
\end{aligned}
$$

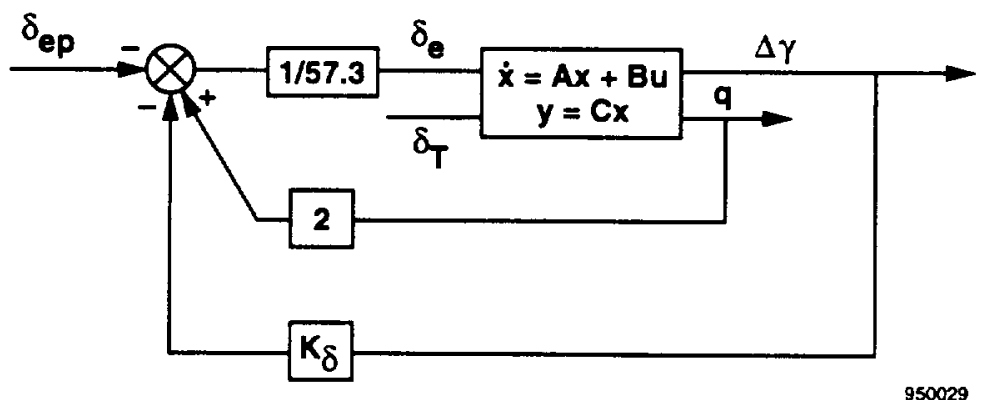

Figure A-1. Longitudinal block diagram. 
Phugoid instabilities were introduced by varying the control system gain, $K_{\delta}$, with the values listed in table 2 in order to obtain their corresponding instabilities. The rest of the control system gains remained constant. Height mode instabilities were introduced by varying the value of $C_{D_{v}}$ (table 3 ). Varying $C_{D_{v}}$ had the effect of varying only the element $X$ in matrix $A$; all the other elements in both the $A$ and $B$ matrices were constant. Table A-l shows the $K_{\delta}, \mathrm{C}_{\mathrm{D}_{\mathrm{v}}}$, and $\mathrm{X}$ values for both phugoid and height mode variations.

\section{LATERAL-DIRECTIONAL EQUATIONS}

Figure A-2 shows the lateral-directional block diagram. Pilot inputs are described by $\delta_{a p}$ and $\delta_{r p}$ for the lateral stick deflection and rudder pedal inputs respectively. The linear aircraft equations of motion are represented by the state-space equation. The lateral-directional control system gains and state-space matrices remained constant throughout both phugoid and height mode evaluations. The state-space matrices are as follows:
Table A-1. Constants required for implementing height and phugoid mode variations.

\begin{tabular}{lccc}
\hline \hline & $K_{\delta}$ & $C_{D_{v}}$ & $X$ \\
\hline & 0 & & \\
& 4.2 & & \\
Phugoid mode variations & 10 & 0 & $-0.22 \times 10^{-2}$ \\
& 20 & & \\
& 25 & & \\
& 30 & & \\
\hline & & 0.00001 & $-0.89 \times 10^{-2}$ \\
& & -0.00003 & $0.18 \times 10^{-1}$ \\
& & -0.00006 & $0.38 \times 10^{-1}$ \\
& 0 & -0.00008 & $0.51 \times 10^{-1}$ \\
& & -0.00018 & 0.12 \\
& & -0.00024 & 0.16 \\
& & -0.00030 & 0.2 \\
\hline \hline
\end{tabular}

$$
\begin{aligned}
& A=\left|\begin{array}{ccccc}
-0.79 \times 10^{-1} & 0.19 \times 10^{-1} & 0.96 & 0.18 \times 10^{-5} & -0.42 \times 10^{-} \\
-0.43 \times 10^{-3} & -0.62 \times 10^{-2} & 3.76 & 0.70 \times 10^{-5} & -0.16 \times 10^{-6} \\
0.143 & -0.99 & -0.17 \times 10^{-1} & 0.31 \times 10^{-2} & 0.30 \times 10^{-8} \\
1 & 0.14 & -0.48 \times 10^{-3} & -0.86 \times 10^{-5} & 0.61 \times 10^{-4} \\
0 & 1 & -0.69 \times 10^{-4} & -0.53 \times 10^{-3} & 0.86 \times 10^{-5}
\end{array}\right| \\
& \mathrm{B}=\left|\begin{array}{cc}
5.1 & 1.2 \\
0.20 \times 10^{-1} & -0.75 \times 10^{-1} \\
0.91 \times 10^{-4} & 0.86 \times 10^{-3} \\
0 & 0 \\
0 & 0
\end{array}\right| \mathrm{x}=\left|\begin{array}{c}
p \\
r \\
\beta \\
\phi \\
\psi
\end{array}\right| \quad \mathrm{u}=\mid \begin{array}{c}
\delta_{a} \\
\delta_{r}
\end{array} \\
& \mathrm{C}=\left|\begin{array}{ccccc}
57.3 & 0 & 0 & 0 & 0 \\
0 & 57.3 & 0 & 0 & 0 \\
0 & 0 & 57.3 & 0 & 0 \\
0 & 0 & 0 & 57.3 & 0 \\
0 & 0 & 0 & 0 & 57.3
\end{array}\right|
\end{aligned}
$$




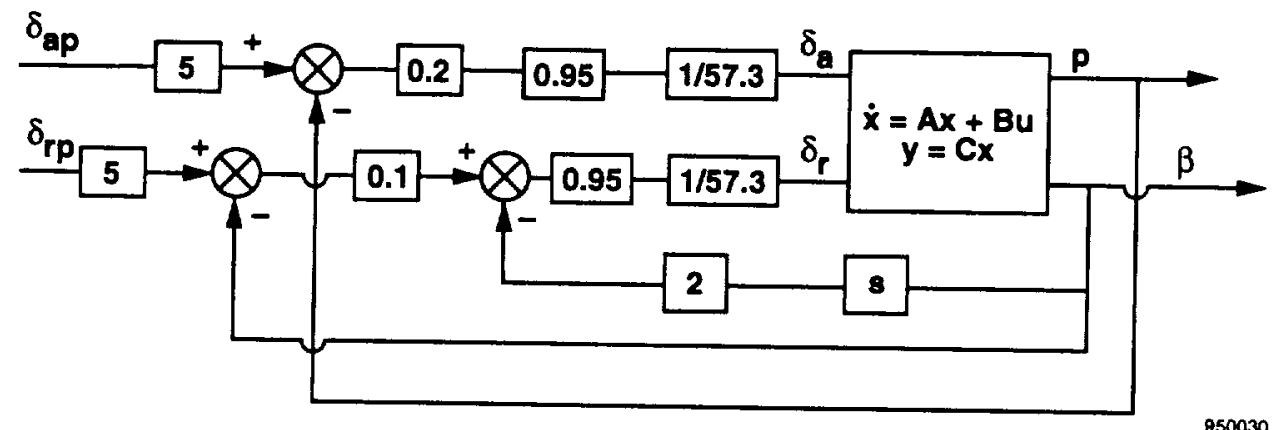

Figure A-2. Lateral-directional block diagram. 
Publicreportingburdenforthiscollectionofinformation is estimatedioaverage 1 hourperresponse, includingthe time forreviewing instructions, searching existing data sources. gatheringandmaintaining thedataneeded, and completing and reviewingthecollection of intormation. Sendcomments regarding this burden estimaleor anyother aspect of this

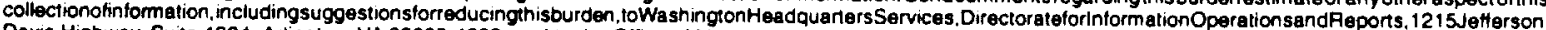
Davis Highway, Suite 1204, Arlington, VA 22202-4302, and to the Office of Management and Budget, Paperwork Reduction Project (0704-0188). Washington. DC 20503.

\begin{tabular}{|l|c|c|}
\hline 1. AGENCY USE ONLY (Leave blank) & $\begin{array}{c}\text { 2. REPORT DATE } \\
\text { April } 1995\end{array}$ & $\begin{array}{l}\text { 3. REPORT TYPE AND DATES COVERED } \\
\text { Technical Memorandum }\end{array}$ \\
\hline
\end{tabular}

4. TITLE AND SUBTITLE 5. FUNDING NUMBERS

A Flying Qualities Study of Longitudinal Long-Term Dynamics of Hypersonic Planes

T. Cox, G. Sachs, A. Knoll, and R. Stich

7. PERFoRMING ORGANIZATION NAME(S) AND ADDRESS(ES)

NASA Dryden Flight Research Center

P.O. Box 273

Edwards, California 93523-0273
Technische Universität München Lehrstuhl f. Flugmechanik

Arcisstrasse 21

80290 München
8. PERFORMING ORGANIZATION REPORT NUMBER

H-2034

10. SPONSORINGMONTORING AGENCY REPORT NUMBER

NASA TM-104308

Technical University of Munich

Munich, Germany

11. SUPPLEMENTARY NOTES

Prepared for the American Institute of Aeronautics and Astronautics Sixth International Aerospace Planes and Hypersonics Technologies Conference in Chattanooga, Tennessee, April 3-7, 1995.

12a. DISTRIBUTIONVAVAILABILITY STATEMENT

12b. DISTRIBUTION CODE

Unclassified-Unlimited

Subject Category 05

13. ABSTRACT (Maximum 200 words)

The NASA Dryden Flight Research Center and the Technical University of Munich are cooperating in a research program to assess the impact of unstable long-term dynamics on the flying qualities of planes in hypersonic flight. These flying qualities issues are being investigated with a dedicated flight simulator for hypersonic vehicles located at NASA Dryden. Several NASA research pilots have flown the simulator through well-defined steady-level turns with varying phugoid and height mode instabilities. The data collected include pilot ratings and comments, performance measurements, and pilot workload measurements. The results presented in this paper include design guidelines for height and phugoid mode instabilities, an evaluation of the tapping method used to measure pilot workload, a discussion of techniques developed by the pilots to control large instabilities, and a discussion of how flying qualities of unstable long-term dynamics influence control power design requirements.

\begin{tabular}{|c|c|c|c|}
\hline \multirow{2}{*}{\multicolumn{3}{|c|}{$\begin{array}{l}\text { 14. SUBJECT TERMS } \\
\text { Hypersonics, Flying Qualities, Phugoid Mode, Height Mode, Long-Term Dynamics, } \\
\text { Pilot Workload, Workload Estimation, Tapping Method }\end{array}$}} & \multirow{2}{*}{ 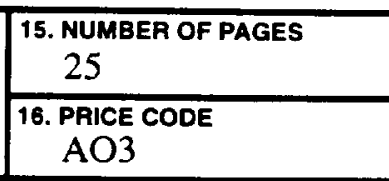 } \\
\hline & & & \\
\hline $\begin{array}{l}\text { 17. SECUATYY CLASSIFICATION } \\
\text { OF REPOPT } \\
\text { Unclassified }\end{array}$ & $\begin{array}{l}\text { 18. SECURTRY CLASSIFICATION } \\
\text { OF THIS PAGE } \\
\text { Unclassified }\end{array}$ & $\begin{array}{l}\text { 19. SECUATYY CLASSIFICATION } \\
\text { OF ABSTRACT } \\
\text { Unclassified }\end{array}$ & $\begin{array}{l}\text { 20. LIMITATION OF ABSTRACT } \\
\text { Unlimited }\end{array}$ \\
\hline
\end{tabular}

